\title{
Improving Riverine Constituent Concentration and Flux Estimation by Accounting for
}

\section{Antecedent Discharge Conditions}

\author{
Qian Zhang $^{\mathrm{a},{ }^{*}, 1}$, William P. Ball ${ }^{\mathrm{a}, \mathrm{b}}$ \\ ${ }^{a}$ Johns Hopkins University, Department of Geography and Environmental Engineering, 3400 North Charles \\ Street, Ames Hall 313, Baltimore, MD 21218, USA \\ ${ }^{\mathrm{b}}$ Chesapeake Research Consortium, 645 Contees Wharf Road, Edgewater, MD 21037, USA \\ *Corresponding author. Tel.: +1-410-267-5794; E-mail address: qzhang@ chesapeakebay.net. \\ ${ }^{1}$ Present address: University of Maryland Center for Environmental Science / U.S. Environmental Protection \\ Agency Chesapeake Bay Program, 410 Severn Avenue, Suite 112, Annapolis, MD 21403, USA \\ E-mail addresses: qzhang@chesapeakebay.net (Q. Zhang), bball@jhu.edu (W. Ball).
}

\begin{abstract}
Regression-based approaches are often employed to estimate riverine constituent concentrations and fluxes based on typically sparse concentration observations. One such approach is the recently developed WRTDS ("Weighted Regressions on Time, Discharge, and Season") method, which has been shown to provide more accurate estimates than prior approaches in a wide range of applications. Centered on WRTDS, this work was aimed at developing improved models for constituent concentration and flux estimation by accounting for antecedent discharge conditions. Twelve modified models were developed and tested, each of which contains one additional flow variable to represent antecedent conditions and which can be directly derived from the daily discharge record. High-resolution ( daily) data at nine diverse monitoring sites were used to evaluate the relative merits of the models for estimation of six constituents - chloride $(\mathrm{Cl})$, nitrate-plus-nitrite $\left(\mathrm{NO}_{\mathrm{x}}\right)$, total Kjeldahl nitrogen $(\mathrm{TKN})$, total phosphorus (TP), soluble reactive phosphorus (SRP), and suspended sediment (SS). For each
\end{abstract}


site-constituent combination, 30 concentration subsets were generated from the original data through Monte Carlo subsampling and then used to evaluate model performance. For the subsampling, three sampling strategies were adopted: (A) 1 random sample each month (12/year), (B) 12 random monthly samples plus additional 8 random samples per year (20/year), and (C) flow-stratified sampling with 12 regular (non-storm) and 8 storm samples per year (20/year). Results reveal that estimation performance varies with both model choice and sampling strategy. In terms of model choice, the modified models show general improvement over the original model under all three sampling strategies. Major improvements were achieved for $\mathrm{NO}_{\mathrm{x}}$ by the long-term flow-anomaly model and for $\mathrm{Cl}$ by the ADF (average discounted flow) model and the short-term flow-anomaly model. Moderate improvements were achieved for SS, TP, and TKN by the ADF model. By contrast, no such achievement was achieved for SRP by any proposed model. In terms of sampling strategy, performance of all models (including the original) was generally best using strategy $\mathrm{C}$ and worst using strategy A, and especially so for SS, $\mathrm{TP}$, and SRP, confirming the value of routinely collecting stormflow samples. Overall, this work provides a comprehensive set of statistical evidence for supporting the incorporation of antecedent discharge conditions into the WRTDS model for estimation of constituent concentration and flux, thereby combining the advantages of two recent developments in water quality modeling.

\section{Keywords}

River flux estimation; flow anomalies; antecedent discharge; nutrients; sediment; river water quality monitoring. 


\section{Introduction}

In many river monitoring programs, flow discharge is usually recorded daily but water quality constituent concentration has been historically sampled at low frequency, and rarely at more than a few times each month. In the United States, there are numerous locations where the U.S. Geological Survey and others have maintained long-term records of flow every fifteen minutes for decades, but where water quality sampling has been far less frequent. For example, even at sites of comparatively long-term monitoring, such as in tributaries of the Chesapeake Bay, where there is a roughly 30 -year record of water quality sampling, the number of annual samples has typically ranged between 20 and 50, usually comprising at least 12 regular monthly samples and 8 targeted stormflow samples (Chanat et al., 2016; Zhang et al., 2016a). Water quality monitoring data at many other discretely sampled locations generally have even lower temporal resolutions. In using such sparse data toward load estimation, it is important to make best possible estimates of concentration for each day in the record, thus enabling calculation of daily flux ("load") as the product of daily concentration and daily discharge. From a management perspective, such daily estimates and their temporal aggregates (monthly, seasonal, or annual averages) play an essential role toward assessment against regulatory standards (e.g., maximum concentration levels), establishment and assessment of restoration targets (e.g., total maximum daily loads), calibration of watershed models, and evaluation of long-term trends in surface water quality (Bowes et al., 2008; Shenk and Linker, 2013; Stow and Borsuk, 2003; Zhang et al., 2015).

Over the last few decades, alternative regression-based approaches have been developed by various investigators, including but not limited to, Cohn et al. (1992); Cohn et al. (1989); Crowder et al. (2007); Dolan et al. (1981); Johnes (2007); Kronvang and Bruhn (1996); Park and 
Engel (2015); and Stenback et al. (2011). These approaches generally estimate daily

concentrations and fluxes based on modeled relations between observed concentration and some set of explanatory variables, which typically include time, discharge, and season. With these covariates, a single regression model is usually established for the entire record based on common assumptions of homoscedasticity of model errors and fixed relations between concentration and each covariate. These assumptions, however, can be frequently violated in reality - see examples in Hirsch et al. (2010).

With consideration of the above limitations, Hirsch et al. (2010) developed a method called "Weighted Regressions on Time, Discharge, and Season (WRTDS)". Similar to the prior approaches, WRTDS makes use of time, discharge, and season as explanatory variables but has a major distinction in that it develops a separate regression model for each day in the record. For each day, it re-evaluates the dependencies of concentration on time, discharge, and season based on data deemed to be most relevant to the day of estimation (Hirsch and De Cicco, 2015; Hirsch et al., 2010). Consequently, WRTDS can better represent the temporally varying seasonal and discharge-related patterns and is more resistant to problems of flux-estimation bias than prior methods (Hirsch, 2014; Moyer et al., 2012). Since its publication in 2010, WRTDS has been applied in a suite of large-scale studies (Chanat et al., 2016; Corsi et al., 2015; Hirsch, 2012; Medalie et al., 2012; Moyer et al., 2012; Murphy et al., 2014; Pellerin et al., 2014; Sprague et al., 2011; Zhang et al., 2016a; Zhang et al., 2013; Zhang et al., 2015; Zhang et al., 2016b).

Although WRTDS represents an advance relative to prior approaches, it is of course eligible for further improvement. In this context, the original authors suggested that additional explanatory variables, perhaps especially those that can account for watershed wetness conditions, may further enhance the model (Hirsch et al., 2010). Mechanistically, antecedent 
conditions can influence both the momentum and pathways of constituent transport from watershed to stream. In a relatively dry watershed, particulate constituents tend to be kept locally and dissolved constituents may enter the subsurface near their point of application or generation. When the watershed becomes wetter, particulate constituents can be more easily mobilized with surface runoff and dissolved constituents can be more efficiently flushed to stream due to saturation of subsurface storage (Cirmo and McDonnell, 1997; Dupas et al., 2015; Inamdar et al., 2004). In the last two decades, an extensive set of literature has documented the effects of antecedent condition on riverine export of constituents, including nitrogen (Biron et al., 1999; Davis et al., 2014; Macrae et al., 2010; Murphy et al., 2014; Turgeon and Courchesne, 2008), phosphorus (Ide et al., 2008; Macrae et al., 2010; McDowell and Sharpley, 2002; Warner et al., 2009), suspended sediment (Gray et al., 2015; McDowell and Sharpley, 2002), and dissolved organic carbon (Biron et al., 1999; Turgeon and Courchesne, 2008). Of special relevance to the current work, Vecchia (2003) has developed the flow anomaly concept for quantification of antecedent discharge conditions, which has been subsequently used and refined in numerous analyses of surface water quality (Ryberg and Vecchia, 2014; Vecchia, 2005; Vecchia et al., 2009; Vecchia et al., 2008). In the context of WRTDS, Murphy et al. (2014) have previously considered Vecchia's approach, but that work was a preliminary effort of limited scope and depth, with evaluation of only a limited set of antecedent condition variables and with a particular focus on nitrate transport.

The overall objective of the study described here was to substantially expand upon the work of Murphy et al. (2014) by developing and rigorously testing several alternative statistical models that build on the WRTDS model by also accounting for antecedent discharge conditions, thereby providing improved estimation of riverine concentration and flux. For method 
transferability, we focused on variables that can be directly derived from the daily river discharge record, since such record is typically available regardless of watershed characteristics or geographical regions. These variables include flow anomalies on various temporal scales (Ryberg and Vecchia, 2014; Vecchia et al., 2009), average discounted flow (Wang et al., 2011; Wang and Tian, 2013), base-flow index (Lyne and Hollick, 1979; Nathan and McMahon, 1990), and flow gradient (see Section 2). Six constituents were evaluated, namely, chloride (Cl), nitrateplus-nitrite $\left(\mathrm{NO}_{\mathrm{x}}\right)$, total Kjeldahl nitrogen $(\mathrm{TKN})$, total phosphorus (TP), soluble reactive phosphorus (SRP), and suspended sediment (SS), using high-resolution (nearly daily) data at nine diverse monitoring sites (Section 3.1). For each site-constituent combination, concentration subsets were generated through Monte Carlo subsampling, which was conducted based on three different sampling strategies to mimic common monitoring practice (Section 3.2). Finally, model estimates were compared with observations to evaluate the performance of the original and modified models (Section 3.3).

\section{Statistical Models: Original and Modified WRTDS}

The original WRTDS model uses the following principle equation (Hirsch et al., 2010):

$$
\ln (C)=\beta_{0}+\beta_{1} t+\beta_{2} \ln (Q)+\beta_{3} \sin t(2 \pi t)+\beta_{4} \cos (2 \pi t)+\varepsilon
$$

where $C$ is constituent concentration, $t$ is time in decimal years, $Q$ is daily discharge, $\beta_{i}$ are fitted coefficients, and $\varepsilon$ is the error term. On the right side of the equation, the $2^{\text {nd }}$ and $3^{\text {rd }}$ terms represent time and discharge effects, respectively, while the $4^{\text {th }}$ and $5^{\text {th }}$ terms represent seasonal effects. The $\ln (C) \sim \ln (Q)$ relationship is adopted for three reasons. First, it provides a generally better fit than a linear relationship. Second, the residuals from this model are more nearly normal and homoscedastic. Third, it avoids the possibility of obtaining negative values for estimated concentration (Hirsch and De Cicco, 2015). For each day in the record, WRTDS develops one 
separate regression model to estimate concentration and flux. First, it pre-screens the entire concentration data set and selects at least 100 samples that are sufficiently "close" to the estimation day in three dimensions, i.e., time, season, and discharge. For these three dimensions, default half-window widths are 7 years, 0.5 year, and 2 natural log units, respectively. Second, the selected samples are used to build a weighted regression model based on Equation 1. Third, the fitted coefficients are used to estimate $\ln (C)$ on the estimation day by substituting known values of $t$ and $Q$, which is then transformed to concentration in real space using a proper bias correction factor. (Note that the set of fitted model coefficients is unique for each day of estimation.) Finally, the estimated $C$ is multiplied by daily $Q$ to calculate daily flux. Full details of the above estimation process are described in Hirsch and De Cicco (2015).

To account for antecedent discharge conditions, we modified Equation 1 by adding one of several alternative flow variables. For model parsimony, only one new variable was added in each modified model, as represented by $\boldsymbol{X}$ in Equation 2:

$$
\ln C=\beta_{0}+\beta_{1} t+\beta_{2} \ln Q+\beta_{3} \sin t(2 \pi t)+\beta_{4} \cos (2 \pi t)+\beta_{5} X+\varepsilon
$$

The alternative variables for $\boldsymbol{X}$ include flow anomalies (FA) on various temporal scales, average discounted flow (ADF), base-flow index (BFI), and flow gradient ( $d Q / d t)$, all of which can be directly derived from the daily discharge record. These terms are defined below in Equations 315. In general, antecedent discharge variables quantified at a river monitoring site (i.e., the outlet of a watershed) can be used as a proxy for antecedent moisture conditions across the watershed by amalgamating highly variable soil water and groundwater storage conditions caused by spatially varying climatic, hydrogeologic, and land use conditions across the watershed (Murphy et al., 2014). Depending upon the characteristics of the watershed and the water quality variable of interest, one might expect different timescales of antecedent condition to be relevant, such that 
different model selections may be more appropriate for different constituent-watershed combinations.

The FA term quantifies how different (how "anomalous") the antecedent discharge conditions actually are for the selected temporal scale of the FA term and for the given day on which the analysis is conducted. For any given day, the FA term can be defined with the following general form (Ryberg and Vecchia, 2014; Vecchia et al., 2009):

$$
F A(t)=X_{T_{1}}(t)-X_{T_{2}}(t)
$$

where $X_{T_{1}}(t)$ and $X_{T_{2}}(t)$ are averages of log-transformed daily discharge for periods of $T_{1}$ and $T_{2}$ preceding a given day $t$, with $T_{l}$ as the shorter of the two periods. With this definition, a positive value of FA corresponds to a situation in which the shorter-term (more recent) period has been "wetter" (has experienced more average rainfall and riverflow) than the longer-term (precedent) period. In this work, flow anomalies were quantified for varying groups of temporal scales using the $R$ package "waterData" (Ryberg and Vecchia, 2014), which are described below and should be interpreted with the general definition in Equation 3.

Long-term FA (preceding 1-year $v s$. entire period):

$$
\operatorname{LTFA}(t)=X_{1 \text { year }}(t)-X_{\text {entire period }}
$$

Mid-term FA (preceding 1-month $v s$. preceding 1-year):

$$
\operatorname{MTFA}(t)=X_{1 \text { month }}(t)-X_{1 \text { year }}(t)
$$

Short-term FA (current day $v s$. preceding 1-month):

$$
S \operatorname{TFA}(\mathrm{t})=X_{\text {current day }}(t)-X_{1 \text { month }}(t)
$$

Annual FA (preceding 1-year $v s$. preceding 5-year):

$$
\operatorname{AnnualF} A(t)=X_{1} \text { year }(t)-X_{5 \text { year }}(t)
$$

Seasonal FA (preceding quarter-year $v s$. preceding 1-year): 


$$
\operatorname{SeasonF} A(t)=X_{1 / 4 \text { year }}(t)-X_{1 \text { year }}(t)
$$

Daily FA (current day $v s$. preceding quarter-year):

$$
\operatorname{DailyF} A(t)=X_{\text {current day }}(t)-X_{1 / 4 \text { year }}(t)
$$

100-day FA (preceding 100-day $v s$. entire period):

$$
F \mathrm{~A} 100(\mathrm{t})=\mathrm{X}_{100 \text { day }}(\mathrm{t})-X_{\text {entire period }}
$$

10-day FA (preceding 10-day $v s$. preceding 100-day):

$$
F A 10(t)=X_{10 \text { day }}(t)-X_{100 \text { day }}(t)
$$

1-day FA (current day $v s$. preceding 10-day):

$$
F A 1(t)=X_{\text {current day }}(t)-\mathrm{X}_{10 \text { day }}(\mathrm{t})
$$

(Note that the term $X_{\text {entire period }}$ is not a function of $t$, i.e., temporally invariant.) For the work described herein, all of these alternative FA terms (Equations 4-12) were considered in order to test which would most appropriately represent antecedent conditions for the various constituents in a given watershed. For each FA term, a daily-step time series was quantified for the period of record, as illustrated with the Maumee River record in Fig. 1b-1j. (This is one of the nine monitoring sites examined in this work, as described further in Section 3.1.)

The ADF term was originally proposed by Wang et al. (2011) to incorporate the influence of historical flows into flux estimation:

$$
A D F(t)=\frac{\sum_{j=1}^{J} d^{t-t_{j}} Q_{t_{j}}}{\sum_{j=1}^{J} d^{t-t_{j}}}
$$

Where $J$ is the maximum number of daily discharge observations in the record, $t$ is the day of estimation, $t_{j}$ is a historical day relative to $t\left(i . e ., t_{j}<t\right), t-t_{j}$ is the lag time between $t$ and $t_{j}$ $(1 \leq j \leq J)$, and $d$ is the discounting rate. In this work, $d$ was taken to be 0.95 per day $(\sim 0.5$ per fortnight). This term aims to capture the integrated effect of all past flows in terms of flushing 
and exhaustion, with higher weights assigned to more recent flows than those that occurred long time ago (Wang et al., 2011; Wang and Tian, 2013). An example time series of ADF is given in Fig. 1k for Maumee River. So far, the development and application of ADF has been limited to sediment (Wang et al., 2011; Wang and Tian, 2013; Wang et al., 2015). In this work, we seek to compare the effectiveness of $\mathrm{ADF}$ and the other antecedent discharge terms for six common water quality constituents. Operationally, the logarithmic form of ADF was taken as the $\boldsymbol{X}$ term in Equation 2.

The next candidate term for $\boldsymbol{X}$ in Equation 2 is $d Q / d t$, which is simply the first derivative of the daily discharge series at the day of interest:

$$
d Q / d t(t)=Q_{t}-Q_{t-1}
$$

An example time series of $d Q / d t$ is given in Fig. 11 for Maumee River. This term may be effective in capturing the effect of hysteresis, i.e., concentration may vary significantly depending on whether the sampling is occurring on the rising or falling limb of the hydrograph (Bieroza and Heathwaite, 2015; Evans and Davies, 1998).

The last candidate term, BFI, is simply the ratio of baseflow to total stream flow:

$$
B F I(t)=B F(t) / Q(t)
$$

where $B F(t)$ is the baseflow on day $t$, which was calculated using the Lyne-Hollick filter method (Lyne and Hollick, 1979; Nathan and McMahon, 1990) through the R package "EcoHydRology" (Fuka et al., 2014). An example time series of BFI is given in Fig. 1m for Maumee River. Operationally, the logarithmic form of BFI was taken as the $\boldsymbol{X}$ term in Equation 2. As a measure of the slow continuous contribution of groundwater, BFI may be effective in capturing dynamics of subsurface solute transport, particularly $\mathrm{Cl}$ and $\mathrm{NO}_{\mathrm{x}}$ (Böhlke and Denver, 1995; Harman, 2015; Kirchner et al., 2001; Sanford and Pope, 2013). 


\section{Data and Analysis}

\subsection{Testing Sites and Data}

The main body of our work used the above described models with high-resolution (nearly daily) water quality concentration data for several tributaries to Lake Erie and Ohio River, as obtained from the National Center for Water Quality Research at Heidelberg University, Ohio, USA (National Center for Water Quality Research, 2015). Nine sites with at least 15 years of samples were selected, including Maumee River, Scioto River, Great Miami River, Sandusky River, River Raisin, Cuyahoga River, Grand River, Honey Creek, and Rock Creek (Table 1). These sites have all been frequently sampled and cover a wide range of drainage area (34.6 $\left.6,330 \mathrm{mi}^{2}\right)$, agriculture land $(30.4 \% \sim 89.9 \%)$, wooded land $(7.3 \% \sim 50.1 \%)$, and urban land $(0.6 \%$ $\sim 9.6 \%$ ), thus allowing a cursory test of the extent to which each model's results are site-specific or more generally applicable and also providing an initial consideration of the effect of watershed size and characteristics on model selection. Although it was beyond our scope to rigorously investigate the general applicability of the findings, our selection of a suite of different watersheds does at least provide some assurance that the findings are not strictly limited to a single watershed or watershed type.

For each site, concentration data were compiled for six water quality constituents, namely, $\mathrm{Cl}$, $\mathrm{NO}_{\mathrm{x}}, \mathrm{TKN}, \mathrm{TP}, \mathrm{SRP}$, and SS. For each site-constituent combination, the original concentration data were imported from pre-prepared files using the $R$ package "dataRetrieval"(Hirsch and De Cicco, 2015). In some cases, non-positive concentration values were recorded due to a combination of very small true (but unknown) concentrations plus random instrument errors (Dr. Laura Johnson, personnel communication). These values were removed from the data sets, because (1) these values make no physical sense and (2) the original and modified WRTDS 
models can never generate negative estimates due to the logarithmic operation (Equation 1). For days with multiple concentration measurements, their median value was used. The average number of sampled days ranges between 256 and 349 per year. (See details in Table 2.) In addition, daily river discharge data at each site were directly imported from the U.S. Geological Survey National Water Information System (U.S. Geological Survey, 2015) using the $R$ package "dataRetrieval" (Hirsch and De Cicco, 2015). Time series of the proposed flow variables were calculated using the respective equations and associated $R$ packages, as described in Section 2.

\subsection{Monte Carlo Subsampling}

To mimic the roughly monthly sampling frequency in many monitoring programs, we performed Monte Carlo subsampling of the original concentration data to produce concentration subsets for subsequent model evaluation. Three common sampling strategies were considered:

(A) One concentration sample was randomly selected for each calendar month for which concentration samples were available (i.e., 12 concentration samples per year),

(B) 12 random monthly samples plus additional 8 random samples per year (i.e., 20 concentration samples per year), and

(C) Flow-stratified sampling with 12 regular samples and 8 storm samples per year (20 concentration samples per year). Within each specific year of the record, samples with daily discharge exceeding the $90^{\text {th }}$ percentile of daily discharge distribution of the year were marked as "storm sample"; all other samples were considered as "regular samples". Because this sampling strategy has been adopted for many river monitoring sites within the Chesapeake Bay watershed (see details in Chanat et al. (2016)), evaluation of model performance for this sampling strategy can provide important insights toward the design and maintenance of the Chesapeake Bay watershed monitoring network and other 
similarly designed monitoring programs in other watersheds.

The original concentration data and the three types of subsamples are illustrated in Fig. 2 for $\mathrm{NO}_{\mathrm{x}}$ in Maumee River.

To formally assign uncertainties on WRTDS estimates, one approach is to use the blockbootstrap method of Hirsch et al. (2015), which involves resampling (with replacement) of the original concentration data to obtain many realizations of representative sets and associated estimates. See Zhang et al. (2016b) for example applications. In this work, for each siteconstituent combination, 30 subsets were independently generated for each of the three sampling strategies, in order to reduce the required total computational time, whilst providing a sufficient number of replicates to reasonably describe overall uncertainties in each model's performance.

\subsection{Model Evaluation}

With each concentration subset, the original and modified models (13 in total) were run to estimate daily concentration and flux, which was implemented in $R$ using codes modified after the existing WRTDS package "EGRET" (Hirsch and De Cicco, 2015). These estimates were then compared against actual observations for calculation of model residuals $\left(Y_{i}^{\text {residual }}\right)$ :

$$
Y_{i}^{\text {residual }}=Y_{i}^{o b s}-Y_{i}^{e s t}
$$

where $Y_{i}^{\text {obs }}$ and $Y_{i}^{\text {est }}$ are observed and modeled values for the $\mathrm{i}^{\text {th }}$ day, respectively. $Y_{i}^{\text {residual }}$ can be interpreted as the portion of concentration (or flux) not accounted for by a specific model. Positive and negative residuals indicate under- and over-estimation, respectively. In addition, Spearman's correlation coefficient $(\gamma)$ was also quantified to examine structural relationships between the residuals from the original WRTDS model and each of the proposed flow variables (Helsel and Hirsch, 2002). Intuitively, a high correlation coefficient may imply that the associated flow variable has a high potential for improving the estimation performance. 
To facilitate performance comparison among the 13 models, three common numerical measures were considered - namely, Nash-Sutcliffe efficiency (NSE), modified NSE (E), and percent bias (PBIAS), as defined below (Krause et al., 2005; Moriasi et al., 2007):

$$
\begin{gathered}
N S E=1-\left[\sum_{i=1}^{n}\left(Y_{i}^{\text {obs }}-Y_{i}^{\text {est }}\right)^{2} / \sum_{i=1}^{n}\left(Y_{i}^{\text {obs }}-Y_{i}^{\text {mean }}\right)^{2}\right] \\
E=1-\left[\sum_{i=1}^{n}\left|Y_{i}^{\text {obs }}-Y_{i}^{\text {est }}\right| / \sum_{i=1}^{n}\left|Y_{i}^{\text {obs }}-Y_{i}^{\text {mean }}\right|\right] \\
\text { PBIAS }=\left[\sum_{i=1}^{n}\left(Y_{i}^{\text {obs }}-Y_{i}^{\text {est }}\right) / \sum_{i=1}^{n}\left(Y_{i}^{\text {obs }}\right)\right] \times 100
\end{gathered}
$$

where $Y_{i}^{o b s}$ and $Y_{i}^{\text {est }}$ are defined as above, $Y_{i}^{\text {mean }}$ is the average of observed data in the record, and $n$ is the total number of observations. NSE quantifies the squared difference between the estimated and observed values normalized by the variance of observations. A model that perfectly matches available observations has NSE $=1$, with values $<0$ representing inferior levels of fit (Krause et al., 2005; Moriasi et al., 2007). Despite being the most common measure, NSE is very sensitive to large errors (i.e., large differences between estimated and observed values) due to the square operation. To deal with this issue, the second measure $\mathrm{E}$ uses absolute differences instead of squared differences. As with NSE, a perfectly accurate model has $\mathrm{E}=1$. Unless otherwise noted, results documented herein are based on E. Finally, PBIAS measures the average tendency of the estimates to be larger or smaller than observations. A perfectly accurate model has PBAIS $=0$. In this work, for each constituent ( 6 in total) at each site ( 9 in total), the three performance measures were calculated for each model (13 in total) in each replicate run (30 for each of three considered sampling strategies).

\section{Results and Discussion}

This section is organized as follows. In Section 4.1, we describe two cases where modified models show major improvement over the original model. In Section 4.2, we present the overall performance of all models based on results at all nine sites. Focus here is on the effects of model 
choices on estimation performance. For brevity, the presented results are associated with sampling strategy "A" unless otherwise noted. In Section 4.3, we elaborate the effects of sampling strategies on model performance.

\subsection{Selected Cases with Major Improvement in Performance}

\subsubsection{Case 1: LTFA Model for $\mathrm{NO}_{x}$ Estimation in Grand River}

The first case considered here is $\mathrm{NO}_{\mathrm{x}}$ in Grand River. For this parameter, concentration residuals from the original WRTDS model appear to fluctuate around zero over time, indicating low bias for the original model (Fig. 3a). There exists, however, a clear negative correlation (Spearman's $\gamma=-0.27$ ) between the original model residuals and LTFA values (Fig. 3b). In other words, large positive LTFA values correspond to negative residuals from the original model, and vice versa. Such correlation is likely reflective of a "storage-and-then-release" effect. Specifically, for days with negative LTFAs, the watershed is relatively dry in the preceding 1year and $\mathrm{NO}_{\mathrm{x}}$ is more likely to have accumulated during the dry period (i.e., less regular "flushing"). Consequently, observed $\mathrm{NO}_{\mathrm{x}}$ concentrations on such days tend to be higher for a given flow than those predicted by the original model (i.e., positive residuals). Conversely, for days with large positive LTFAs, relatively wet watershed conditions existed in the preceding 1year (relative to the entire record), and this likely corresponds with more regular "flushing" of $\mathrm{NO}_{\mathrm{x}}$ and less storage. Thus, observed concentrations on these days are likely to be lower than those predicted by the original model (i.e., negative residuals).

Given the above considerations, we hypothesized that the original WRTDS model can be improved by adding LTFA per Equation 2. This hypothesis was validated by comparing residuals of the LTFA model and those of the original model (Fig. 3c). A more focused look at the majority of data with residual values in the range of $0-2.0 \mathrm{mg} / \mathrm{L}$ (Fig. 3d) clearly reveals 
more points below the 1:1 reference line, reflecting smaller positive residuals (i.e., less underestimation) for the LFTA model. Such improvements are achieved primarily for days with highly negative LTFAs, as shown by red (as opposed to green) colors in Fig. 3c and 3d. This is consistent with the discussion above that the original model tends to under-estimate concentrations for days with strongly negative LTFAs. By taking into account the antecedent discharge effect, the LTFA model effectively alleviates that issue. Conversely, for days with positive LTFAs, the LTFA model appears to exacerbate the issue of over-estimation; however, such undesirable cases are much less frequent. Moreover, improvement with the LTFA model is reflected by the time series of annual flow-weighted concentration - compared with the original model, the LTFA model shows annual $\mathrm{NO}_{\mathrm{x}}$ concentration estimates that follow concentration observations much more closely, with markedly improved modeling of extreme concentrations (Fig. 3e).

Overall, the LTFA model provides major improvement over the original model for $\mathrm{NO}_{\mathrm{x}}$ estimation in Grand River, as quantified using numerical measures in Table 3. Compared with the original model, the LTFA model has larger NSE and E values for both concentration and flux. In addition, the LTFA model has much a smaller absolute PBIAS for flux.

\subsubsection{Case 2: STFA Model for Cl Estimation in Maumee River}

The second case considered here is $\mathrm{Cl}$ in Maumee River. Similar to the case presented above, concentration residuals from the original model appear to fluctuate around zero (Fig. 4a). In this case, however, there exists a clear positive correlation $(\gamma=0.48)$ between the original model residuals and STFA values (Fig. $\mathbf{4 b}$ ). In other words, negative STFAs correspond to negative residuals from the original model. Note that in the case of STFA, the comparison is between the current day (as $X_{T_{1}}$ in Equation 3) and the monthly antecedent discharge (as $X_{T_{2}}$ in Equation 3), 
which can be contrasted with the LTFA, where the annual antecedent discharge (as $X_{T_{1}}$ ) is compared to the entire discharge record (as $X_{T_{2}}$ ). Hence, with STFA, a positive (rather than negative) residual corresponds to relatively wet day but a drier antecedent month, whereas with LTFA, negative residual corresponds to a dry antecedent year relative to the full record. As a result, the positive STFA values are what now suggest the dry antecedent conditions of a "storage-and then-release" effect, as opposed to the negative LTFA values for the $\mathrm{NO}_{\mathrm{x}}$ case above. In particular, a negative STFA now represents a relatively wet condition in the preceding 1-month and reflects a period with sustained "flushing" or loss of storage. Consequently, observed $\mathrm{Cl}$ concentrations on such days tend to be lower than those predicted by the original model (i.e., negative residuals). These interpretations are consistent with the case of LTFA above. Other analyses (results summarized subsequently) revealed that STFA was less effective than LTFA for estimation of $\mathrm{NO}_{\mathrm{x}}$ at Grand River but that STFA was more effective than LTFA for estimation of $\mathrm{Cl}$ at Maumee. We hypothesize that such contrasts reflect differences in response times of the two different constituents in the two different watershed systems. In terms of watershed size alone, the finding might seem somewhat counter-intuitive, because Grand River is the smaller basin (Table 1) yet is better understood in terms of LTFA. These results suggest, perhaps not surprisingly, that parameters other than watershed size controls the time scale at which antecedent discharge is relevant toward regulating riverine concentrations. In this case, the constituent of interest $\left(\mathrm{NO}_{\mathrm{x}} v s . \mathrm{Cl}\right)$ is also important, and a reasonable explanation might be that $\mathrm{Cl}$ response is more sensitive to short-term antecedent discharge relative to the present discharge, whereas $\mathrm{NO}_{\mathrm{x}}$ processing is more sensitive to the past-year discharge relative to the long-term record. The mechanistic underpinnings of these statistical results deserve further investigation. 
As with the $\mathrm{NO}_{x}$ case presented above, the residual-STFA correlation for $\mathrm{Cl}$ in Maumee River led us to hypothesize that the original WRTDS model could be improved by specifically incorporating STFA per Equation 2. Again, the hypothesis was validated by the comparison see Fig. $\mathbf{4 c - 4 d ~ - ~ a n d ~ a s ~ b e f o r e , ~ t h e r e ~ a r e ~ e v i d e n t l y ~ m o r e ~ p o i n t s ~ b e l o w ~ t h e ~ 1 : 1 ~ r e f e r e n c e ~ l i n e , ~}$ which represent cases where the STFA model has smaller positive residuals (i.e., less model under-estimation) than the original model. Such improvements are generally achieved for days with positive STFAs, as shown with green color. Thus, the STFA model effectively improves the estimation by taking into account the antecedent discharge effect. Conversely, the STFA model appears to exacerbate the issue of over-estimation for days with negative STFAs, but again such undesirable cases are less frequent.

In addition, one can again conduct a comparison of the time series of modeled versus observed values of annual flow-weighted $\mathrm{Cl}$ concentration as a good overall evaluation of model performance. The results (Fig. 4e) reveal that the STFA model estimates follow observed annual concentrations much more closely than do the original model estimates, with markedly improved modeling of extreme concentrations. Moreover, our quantitative measures of fit for the full record again reveal that the STFA model has larger NSE and E values for both concentration and flux as well as smaller absolute PBIAS values for both concentration and flux (Table 3).

\subsection{Performance Comparison for All Model Runs: Effects of Model Choices}

Here we present the overall performance of all models based on results for all nine sites. For brevity, the presented results are associated with sampling strategy A unless otherwise noted. Conclusions are similar based on the other two sampling strategies (see Fig. S1-S2). For quantitative comparison with the original model, it is useful to calculate the ratio of E-values between each modified model and the original model for each replicate run and for each site (i.e., 
30 runs/sites x 9 sites $=270$ cases). These 270 ratios are shown with boxplots in Fig. 5. Simple guidelines for model evaluation were developed. Specifically, the modified models are considered to show (1) major improvement, (2) moderate improvement, and (3) inferior performance, if the E-value ratio falls to the following regions: (1) ratio > 1.2 (as indicated by blue bars in Fig. 5), (2) $1<$ ratio $<1.2$ (grey bars), and (3) ratio $<1.0$ (red bars), respectively.

In addition, Spearman's $\gamma$ was calculated to quantify the correlation between original model residuals and each proposed flow variable for each replicate run and for each site, which can provide some indication with respect to if a certain flow variable may improve the original model (see discussion in Section 4.1). For better comparison of correlation strengths, we use boxplots (Fig. 6) to summarize the absolute correlations (i.e., $|\gamma|$ ) for all 270 model runs (i.e., 30 runs/sites x 9 sites). In general, a flow variable with a high $|\gamma|$ may have a high potential for model improvement.

\subsubsection{Constituents with Major Improvement: $\mathrm{Cl}$ and $\mathrm{NO}_{x}$}

The modified models show generally major improvements in the estimation of $\mathrm{Cl}$ and $\mathrm{NO}_{\mathrm{x}}$. For $\mathrm{Cl}$ (Fig. 5a), most of the modified models have E-value ratio (modified model versus original model) $>1.0$, indicating that the modified models are generally effective in improving $\mathrm{Cl}$ estimation. Among all modified models, ADF, STFA, and FA1 show the highest E-value ratios, with about 25\%-50\% falling into the category of major improvement. The ADF model, in particular, provides a roughly even split between "moderate" and "major" improvement. For $\mathrm{NO}_{\mathrm{x}}($ Fig. 5b), the LTFA model shows the best overall performance, followed by AnnualFA, DailyFA, and FA100. These four models generally have E-value ratio > 1.0. Among these models, LTFA falls into the category of major improvement most frequently. Many other models, 
however, show some occasions of inferior performance relative to the original model (i.e., Evalue ratio < 1.0), including MTFA, STFA, SeasonFA, FA1, ADF, BFI, and particularly $d Q / d t$.

These results are consistent with those obtained from correlation analysis. For $\mathrm{Cl}$, highest $|\gamma|$ values are associated with STFA, FA1, and ADF (Fig. 6a). In terms of the correlation sign, STFA consistently shows positive $\gamma$ with the original model residuals (Fig. S3a). For $\mathrm{NO}_{\mathrm{x}}$, LTFA shows the highest $|\gamma|$ among all variables (Fig. 6b) and the $\gamma$ sign is always negative (Fig. S3b). These $\gamma$ signs are consistent with the two cases presented in Section 4.1.

Comparing LTFA with STFA, we observe a phenomenon previously discussed in the context of our two case examples - i.e., that LTFA is more effective for $\mathrm{NO}_{\mathrm{x}}$ estimation, whereas STFA is more effective for $\mathrm{Cl}$ estimation. The key distinction between these two terms lies in the temporal scale for quantification of antecedent conditions. Specifically, LTFA compares average discharges in the preceding 1-year and in the entire record (Equation 4), whereas STFA compares discharge on the day of estimation and average discharge in the preceding 1-month (Equation 6). Thus, "wet antecedence" is a wet month relative to the estimation day for STFA, but a wet year relative to the entire record for LTFA. The relatively longer temporal scale of antecedent relevance for $\mathrm{NO}_{\mathrm{x}}$ than $\mathrm{Cl}$ may reflect the relevance of long-term biogeochemical processes that convert ammonia and organic nitrogen to $\mathrm{NO}_{\mathrm{x}}$, but will likely also reflect that $\mathrm{NO}_{\mathrm{x}}$ is dominantly applied to pervious land through atmospheric deposition and fertilizer application, such that it is more likely to reflect transport through deep and long pathways in the groundwater system (Böhlke and Denver, 1995; Sanford and Pope, 2013). By contrast, $\mathrm{Cl}$ is heavily influenced by winter road salt applications in urban and suburban areas, which are either rapidly flushed to the river channel or temporally stored in the shallow groundwater system and later slowly released via baseflow (Corsi et al., 2015). To verify these or other possible explanations, 
further investigation is required to better understand and compare the source and fate of the two constituents in these watersheds as well as watersheds elsewhere that may have very different sizes and land uses. Additionally, it might be useful to consider alternative definitions of FA terms - i.e., comparisons among several FAs that consider antecedent conditions of different durations relative to the entire record.

\subsubsection{Constituents with Moderate Improvement: TKN, TP, and SS}

For TKN (Fig. 5c), TP (Fig. 5e), and SS (Fig. 5f), the ADF model shows the best performance among all considered models, with E-value ratios that are generally > 1.0, although a large proportion of the ratios show only moderate improvement. BFI and STFA also show improved estimation of TKN and TP. The other models, however, show some occasions of inferior performance relative to the original model. In particular, the $d Q / d t$ model is inferior to the original model more often than not, with some E-value ratios far less than 1.0.

Again, these results are consistent with those from correlation analysis. For all three constituents (TKN, TP, and SS), ADF shows the highest $|\gamma|$ with the original model residuals (Fig. 6c, 6e, 6f) and the signs are generally negative (Fig. S3c, Fig. S3e, Fig. S3f), which is similar to the case of LTFA discussed in Section 4.1.2 and reflective of the "storage-and-thenrelease" effect.

\subsubsection{Constituent without Improvement: SRP}

For soluble reactive phosphorus (SRP), none of the modified models shows consistent improvement over the original model (Fig. 5d). In fact, these models have approximately equal probability of being better or worse than the original model. As elsewhere, the results are consistent with those of the correlation analysis: these proposed variables show generally small $|\gamma|($ Fig. 6d) and the correlations generally have mixed signs (Fig. S3d). This may indicate that 
SRP transport have been more influenced by factors other than antecedent conditions, such as physico-chemical sorption and biological uptake processes in the soil horizon and in the river channel. Another possible explanation is that, among all the six constituents analyzed, SRP has the most occurrences of non-positive concentration values (ranging 0\% 12\% among the nine sites with a median of 7\%). These values were excluded from our analysis, which may have biased the samples' probability distributions and thus the quantification of models' performance.

\subsection{Performance Comparison for All Model Runs: Effects of Sampling Strategies}

\subsubsection{Original Model: Performance under Different Sampling Strategies}

Estimation performance of the original model clearly varies with sampling strategies, as shown in Fig. 7. Based on E-values for concentration, estimation performance generally follows the order of strategy C > strategy B > strategy A, especially for SS and SRP (Fig. 7a). Based on E-values for flux, estimation performance follows the same order, with SS, TP, and SRP showing the strongest improvement with strategy C (Fig. 7b). Similarly, based on absolute percent bias (|PBIAS|), estimation performance for both concentration and flux also follows the same order, especially for SS, TP, and SRP (Fig. 7c-7d). By contrast, such improvement with strategy $\mathrm{C}$ is least strong for the two dissolved constituents, i.e., $\mathrm{Cl}$ and $\mathrm{NO}_{\mathrm{x}}$, particularly for concentration estimation.

These results provide several important insights with respect to the effects of sampling strategy on estimation performance. First, the overall better performance with strategy B relative to strategy A illustrates the value of collecting additional water quality samples (i.e., 20 vs. 12 samples per year). Second, the overall better performance with strategy C than strategy B indicates the value of routinely collecting highflow samples, assuming that the number of total samples per year is fixed (i.e., 20). Consequently, strategy $\mathrm{C}$ always has the best estimation 
performance (i.e., largest E-value and smallest |PBIAS|). Therefore, increased sampling frequency and special emphasis on storm sampling should continue to be recommended for river monitoring implementation. An area where further investigation may be needed, however, is in regard to finding an optimum ratio of storm sampling versus random sampling and to searching for possible dependence of results on constituent of interest and watershed characteristics.

The results presented herein demonstrate that the effects of sampling strategy on estimation performance vary considerably with the constituent of interest. Among all six constituents considered, SS generally shows overall the least satisfactory performance (lowest E-value and highest |PBIAS| for flux) under all three sampling strategies. Following SS, TP and SRP also show large |PBIAS| values. Interestingly, these three constituents also show strong differences in estimation performance among the three sampling strategies. By contrast, $\mathrm{Cl}, \mathrm{NO}_{\mathrm{x}}$, and $\mathrm{TKN}$ show the smallest $|\mathrm{PBIAS}|$ for both concentration and flux and also show very weak differences in estimation performance among the three sampling strategies. These patterns undoubtedly relate to the different mechanisms of release, transformation, and transport of these constituents. One useful measure to consider in this regard is the coefficient of variation (CV) for observed concentrations. Based on monitoring data at the nine sites, SS has the largest CV among all constituents, followed by TP and SRP (Fig. 8). From statistical theory, a larger CV means that accurate estimation will require a larger number of concentration samples (Haan, 2002). Also, a larger CV indicates that a better coverage of the full hydrograph (i.e., both regular flow events and episodic stormflow events) may be required. This interpretation further highlights the benefits of adopting strategy $\mathrm{C}$ for river water quality sampling, especially for SS, TP, and SRP.

\subsubsection{All Models: Performance under Different Sampling Strategies}


Estimation performance of the modified models also varies with sampling strategies, as shown in Fig. 9-10 and Fig. S4. For brevity, these figures only compare the median values of each performance measure based on all 270 model runs (i.e., 30 runs/sites x 9 sites) for each sampling strategy. The performance measures include E-value for concentration (Fig. 9), E-value for flux (Fig. S4), and |PBIAS| for flux (Fig. 10).

In terms of E-values for concentration, the above-documented improvements with the modified models are observed under all three sampling strategies (Fig. 9a-9c). Specifically, the ADF, STFA, and FA1 models show major improvement in Cl estimation. The LTFA model shows major improvement in $\mathrm{NO}_{\mathrm{x}}$ estimation. The $\mathrm{ADF}$ model shows moderate improvement for SS, TP, and TKN. By contrast, none of the modified models can effectively improve SRP estimation. Comparing the three sampling strategies directly, median E-values for concentration are generally higher for strategy B than A (Fig. 9d), generally higher for strategy C than B (Fig. 9f), and of course, generally higher for strategy C than A (Fig. 9e), and these are most pronounced for SS and SRP. In terms of E-values for flux, the results are similar, with SS, SRP, and TP showing considerable improvement with strategy C (Fig. S4).

In terms of |PBIAS| for flux, estimation performance is also generally the best under strategy C, with absolute bias consistently $<5 \%$ (Fig. 10c). Notably, the $d Q / d t$ model performs much worse than the original model under sampling strategies A and B (Fig. 10a-10b). This candidate variable seems to be a confounding variable in the sense that it compromises the power of the original model's existing independent variables (i.e., time, discharge, and season) in capturing the variability of the independent variable (i.e., concentration). For SS in particular, |PBIAS| values are about $40 \%$ and $20 \%$ under strategy A and strategy B, respectively, which are much higher than those of any of the other models. Such inefficacy (high bias) disappears only under 
strategy $\mathrm{C}$, where routinely collected stormflow samples are available (Fig. 10c). Comparing the three sampling strategies directly, |PBIAS $\mid$ medians for flux are generally smaller for strategy B than A (Fig. 10d), smaller for strategy C than A (Fig. 10e), and smaller for strategy C than B (Fig. 10f), and these patterns are most pronounced for SS, SRP, TP, and TKN (Fig. S4).

\section{Conclusion and Final Remarks}

In this work, we developed and evaluated alternative statistical models for estimation of riverine concentration and flux by accounting for antecedent discharge conditions. Results reveal that estimation performance varies with both model choice and sampling strategy. In terms of model choice, the modified models show general improvement over the original model under all three sampling strategies. Major improvements were achieved for $\mathrm{NO}_{\mathrm{x}}$ by the LTFA model and for $\mathrm{Cl}$ by the ADF model and the STFA model. By contrast, no such achievement was achieved for SRP by any proposed model. In terms of sampling strategy, performance of all models (including the original) was generally best using strategy $\mathrm{C}$ and worst using strategy $\mathrm{A}$, and especially so for SS, TP, and SRP, confirming the value of routinely collecting stormflow samples.

Accurate estimation of riverine constituent concentrations and fluxes has been an active research area for decades and will remain a critical challenge to the hydrological community (Cohn et al., 1992; Cohn et al., 1989; Hirsch, 2014; Hirsch et al., 2010). The major contribution of this work is to provide a comprehensive set of statistical evidence for supporting the incorporation of antecedent discharge into the WRTDS model for improved concentration and flux estimation, thereby combining the advantages of these two recent developments in water quality modeling. In recognition of the need for additional future work, several limitations of this study are acknowledged. First, this study has been limited to only six constituents for nine 
watersheds within a specific geographical location. Model performance may vary for constituents not covered here. In addition, more studies need to be carried in different types of watershed in other geographical regions to place these results into a more generalizable context to inform further improvement of estimation methods. (In this regard, however, there are unfortunately few (if any) data of comparable resolution and duration as the Heidelberg set studied here.) Second, all modified models contain only one additional flow variable for the sake of model parsimony. It is possible that a mixture of these flow terms can better incorporate export dynamics at different temporal scales and thus provide additional improvement. Third, this work examined three sampling strategies that are representative of common monitoring practice, but not strategies with different sampling frequencies (e.g., weekly $v s$. monthly), record lengths (e.g., $10 v s .30$ years), or proportions of routine versus storm sampling. Further understanding of these aspects can help inform the allocation of valuable (and often limited) resources toward river water quality monitoring. Fourth, in addition to the time, discharge, and season windows in the current WRTDS model, an additional window may be introduced for the new variable on antecedent discharge, such that higher weights are assigned to concentration samples that have similar antecedent discharge conditions to the estimation day. Fifth, this work is limited to consideration of WRTDS true-condition estimates. In the current WRTDS framework, there is a flow-normalization algorithm for water quality trend analysis, which is also implemented based on Equation 1, i.e., with time, discharge, and season as model covariates but without any antecedent discharge variable. We expect that antecedent discharge variables may also be considered toward use in the flow-normalization algorithm. Last but not least, this work has focused entirely on traditional monitoring data that derive from infrequently measured water quality samples. With increasing use of new technology that allows very high- 
frequency or even continuous data collection from in-situ probes, a practical challenge facing the hydrological community is how to combine the use of both traditional low-frequency data and in-situ high-frequency data toward riverine water quality analysis and load estimation. Moving forward, there is need for additional research to advance understanding on these aspects and to incorporate all available understanding into the development and upgrade of software that can be broadly applied.

\section{Appendix A. Supplementary Material}

Supplementary data associated with this article can be found, in the online version, at http://dx.doi.org/10.1016/xxx.

\section{Acknowledgements}

This work was supported by the U.S. Geological Survey (G15AC00067), Maryland Water Resources Research Center (2015MD329B), Maryland Sea Grant (NA10OAR4170072 and NA14OAR1470090), and National Science Foundation (CBET-1360415). We would like to thank Bob Hirsch, Lori Sprague, and Skip Vecchia (USGS) for their advices, reviews, and encouragements. We thank Jeffery Chanat (USGS) for sharing the R codes for generating flowstratified subsamples. The National Center for Water Quality Research is acknowledged for collecting and maintaining the high-quality data sets.

\section{References}

Böhlke, J.K., Denver, J.M., 1995. Combined Use of Groundwater Dating, Chemical, and Isotopic Analyses to Resolve the History and Fate of Nitrate Contamination in Two Agricultural Watersheds, Atlantic Coastal Plain, Maryland. Water Resour. Res., 31(9): 2319-2339, doi: 


\subsection{9/95WR01584.}

Bieroza, M.Z., Heathwaite, A.L., 2015. Seasonal variation in phosphorus concentration-discharge hysteresis inferred from high-frequency in situ monitoring. Journal of Hydrology, 524: 333-347, doi: 10.1016/j.jhydrol.2015.02.036.

Biron, P.M., Roy, A.G., Courschesne, F., Hendershot, W.H., Côté, B., Fyles, J., 1999. The effects of antecedent moisture conditions on the relationship of hydrology to hydrochemistry in a small forested watershed. Hydrol. Process., 13(11): 1541-1555, doi: 10.1002/(SICI)1099-

1085(19990815)13:11<1541::AID-HYP832>3.0.CO;2-J.

Bowes, M.J., Smith, J.T., Jarvie, H.P., Neal, C., 2008. Modelling of phosphorus inputs to rivers from diffuse and point sources. Sci. Total Environ., 395(2-3): 125-138, doi:

10.1016/j.scitotenv.2008.01.054.

Chanat, J.G., Moyer, D.L., Blomquist, J.D., Hyer, K.E., Langland, M.J., 2016. Application of a weighted regression model for reporting nutrient and sediment concentrations, fluxes, and trends in concentration and flux for the Chesapeake Bay Nontidal Water-Quality Monitoring Network, results through water year 2012. Scientific Investigations Report 2015-5133, U.S. Geological Survey, Reston, VA, doi: 10.3133/sir20155133.

Cirmo, C.P., McDonnell, J.J., 1997. Linking the hydrologic and biogeochemical controls of nitrogen transport in near-stream zones of temperate-forested catchments: a review. Journal of Hydrology, 199: 88-120, doi: 10.1016/S0022-1694(96)03286-6.

Cohn, T.A., Caulder, D.L., Gilroy, E.J., Zynjuk, L.D., Summers, R.M., 1992. The validity of a simple statistical model for estimating fluvial constituent loads: An Empirical study involving nutrient loads entering Chesapeake Bay. Water Resour. Res., 28(9): 2353-2353, doi: 10.1029/92wr01008.

Cohn, T.A., Delong, L.L., Gilroy, E.J., Hirsch, R.M., Wells, D.K., 1989. Estimating constituent loads. Water Resour. Res., 25(5): 937-942, doi: 10.1029/WR025i005p00937.

Corsi, S.R., De Cicco, L.A., Lutz, M.A., Hirsch, R.M., 2015. River chloride trends in snow-affected urban watersheds: increasing concentrations outpace urban growth rate and are common among all 
seasons. Sci. Total Environ., 508: 488-497, doi: 10.1016/j.scitotenv.2014.12.012.

Crowder, D.W., Demissie, M., Markus, M., 2007. The accuracy of sediment loads when logtransformation produces nonlinear sediment load-discharge relationships. Journal of Hydrology, 336: 250-268, doi: 10.1016/j.jhydrol.2006.12.024.

Davis, C.A., Ward, A.S., Burgin, A.J., Loecke, T.D., Riveros-Iregui, D.A., Schnoebelen, D.J., Just, C.L., Thomas, S.A., Weber, L.J., St. Clair, M.A., 2014. Antecedent Moisture Controls on Stream Nitrate Flux in an Agricultural Watershed. J. Environ. Qual., 43(4): 1494-1503, doi: 10.2134/jeq2013.11.0438.

Dolan, D.M., Yui, A.K., Geist, R.D., 1981. Evaluation of River Load Estimation Methods for Total Phosphorus. J. Great Lakes Res., 7(3): 207-214, doi: 10.1016/s0380-1330(81)72047-1.

Dupas, R., Gascuel-Odoux, C., Gilliet, N., Grimaldi, C., Gruau, G., 2015. Distinct export dynamics for dissolved and particulate phosphorus reveal independent transport mechanisms in an arable headwater catchment. Hydrol. Process., 29(14): 3162-3178, doi: 10.1002/hyp.10432.

Evans, C., Davies, T.D., 1998. Causes of concentration/discharge hysteresis and its potential as a tool for analysis of episode hydrochemistry. Water Resour. Res., 34(1): 129-137, doi: 10.1029/97WR01881.

Fuka, D., Walter, M., Archibald, J., Steenhuis, T., Easton, Z., 2014. EcoHydRology: A community modeling foundation for Eco-Hydrology. R package version 0.4.12.

Gray, A.B., Pasternack, G.B., Watson, E.B., Warrick, J.A., Goñi, M.A., 2015. Effects of antecedent hydrologic conditions, time dependence, and climate cycles on the suspended sediment load of the Salinas River, California. Journal of Hydrology, 525: 632-649, doi: 10.1016/j.jhydrol.2015.04.025.

Haan, C.T., 2002. Statistical Methods in Hydrology. Iowa State University Press, Ames, Iowa.

Harman, C.J., 2015. Time-variable transit time distributions and transport: Theory and application to storage-dependent transport of chloride in a watershed. Water Resour. Res., 51(1): 1-30, doi: 10.1002/2014WR015707. 
Helsel, D.R., Hirsch, R.M., 2002. Statistical Methods in Water Resources, U.S. Geological Survey, Reston, VA, http://pubs.usgs.gov/twri/twri4a3/.

Hirsch, R.M., 2012. Flux of Nitrogen, Phosphorus, and Suspended Sediment from the Susquehanna River Basin to the Chesapeake Bay during Tropical Storm Lee, September 2011, as an indicator of the effects of reservoir sedimentation on water quality. Scientific Investigations Report 2012-5185, U.S. Geological Survey, Reston, VA, http://pubs.usgs.gov/sir/2012/5185/.

Hirsch, R.M., 2014. Large Biases in Regression-Based Constituent Flux Estimates: Causes and Diagnostic Tools. J. Am. Water Resour. Assoc., 50(6): 1401-1424, doi: 10.1111/jawr.12195.

Hirsch, R.M., Archfield, S.A., De Cicco, L.A., 2015. A bootstrap method for estimating uncertainty of water quality trends. Journal of Environmental Modelling and Software, 73: 148-166, doi: 10.1016/j.envsoft.2015.07.017.

Hirsch, R.M., De Cicco, L., 2015. User guide to Exploration and Graphics for RivEr Trends (EGRET) and dataRetrieval: R packages for hydrologic data (version 2.0, February 2015). Techniques and Methods Book 4, Chapter A10, U.S. Geological Survey, Reston, VA, doi: 10.3133/tm4A10.

Hirsch, R.M., Moyer, D.L., Archfield, S.A., 2010. Weighted regressions on time, discharge, and season (WRTDS), with an application to Chesapeake Bay river inputs. J. Am. Water Resour. Assoc., 46(5): 857-880, doi: 10.1111/j.1752-1688.2010.00482.x.

Ide, J., Haga, H., Chiwa, M., Otsuki, K., 2008. Effects of antecedent rain history on particulate phosphorus loss from a small forested watershed of Japanese cypress (Chamaecyparis obtusa). Journal of Hydrology, 352: 322-335, doi: 10.1016/j.jhydrol.2008.01.012.

Inamdar, S.P., Christopher, S.F., Mitchell, M.J., 2004. Export mechanisms for dissolved organic carbon and nitrate during summer storm events in a glaciated forested catchment in New York, USA. Hydrol. Process., 18(14): 2651-2661, doi: 10.1002/hyp.5572.

Johnes, P.J., 2007. Uncertainties in annual riverine phosphorus load estimation: Impact of load estimation methodology, sampling frequency, baseflow index and catchment population density. Journal of Hydrology, 332(1-2): 241-258, doi: 10.1016/j.jhydrol.2006.07.006. 
Kirchner, J.W., Feng, X., Neal, C., 2001. Catchment-scale advection and dispersion as a mechanism for fractal scaling in stream tracer concentrations. Journal of Hydrology, 254(1-4): 82-101, doi: 10.1016/s0022-1694(01)00487-5.

Krause, P., Boyle, D.P., Bäse, F., 2005. Comparison of different efficiency criteria for hydrological model assessment. Adv. Geosci., 5: 89-97, doi: 10.5194/adgeo-5-89-2005.

Kronvang, B., Bruhn, A.J., 1996. Choice of sampling strategy and estimation method for calculating nitrogen and phosphorus transport in small lowland streams. Hydrol. Process., 10(11): 1483-1501, doi: 10.1002/(SICI)1099-1085(199611)10:11<1483::AID-HYP386>3.0.CO;2-Y.

Lyne, V.D., Hollick, M., 1979. Stochastic Time-Variable Rainfall-Runoff Modeling, Hydrology and Water Resources Symposium. Institution of Engineers Australia, Perth, Australia, pp. 89-92.

Macrae, M.L., English, M.C., Schiff, S.L., Stone, M., 2010. Influence of antecedent hydrologic conditions on patterns of hydrochemical export from a first-order agricultural watershed in Southern Ontario, Canada. Journal of Hydrology, 389(1-2): 101-110, doi: 10.1016/j.jhydrol.2010.05.034.

McDowell, R.W., Sharpley, A.N., 2002. The effect of antecedent moisture conditions on sediment and phosphorus loss during overland flow: Mahantango Creek catchment, Pennsylvania, USA. Hydrol. Process., 16(15): 3037-3050, doi: 10.1002/hyp.1087.

Medalie, L., Hirsch, R.M., Archfield, S.A., 2012. Use of flow-normalization to evaluate nutrient concentration and flux changes in Lake Champlain tributaries, 1990-2009. J. Great Lakes Res., 38: 58-67, doi: 10.1016/j.jglr.2011.10.002.

Moriasi, D.N., Arnold, J.G., Van Liew, M.W., Bingner, R.L., Harmel, R.D., Veith, T.L., 2007. Model Evaluation Guidelines for Systematic Quantification of Accuracy in Watershed Simulations. Trans. ASAE, 50(3): 885-900, doi: 10.13031/2013.23153.

Moyer, D.L., Hirsch, R.M., Hyer, K.E., 2012. Comparison of Two Regression-Based Approaches for Determining Nutrient and Sediment Fluxes and Trends in the Chesapeake Bay Watershed. Scientific Investigations Report 2012-5244, U.S. Geological Survey, Reston, VA, http://pubs.usgs.gov/sir/2012/5244/. 
Murphy, J.C., Hirsch, R.M., Sprague, L.A., 2014. Antecedent flow conditions and nitrate concentrations in the Mississippi River basin. Hydrol. Earth Syst. Sci., 18(3): 967-979, doi: 10.5194/hess-18967-2014.

Nathan, R.J., McMahon, T.A., 1990. Evaluation of automated techniques for base flow and recession analyses. Water Resour. Res., 26(7): 1465-1473, doi: 10.1029/WR026i007p01465.

National Center for Water Quality Research, 2015. User's Guide to the River Data Sets. http://www.heidelberg.edu/academiclife/distinctive/ncwqr/data.

Park, Y.S., Engel, B.A., 2015. Analysis for Regression Model Behavior by Sampling Strategy for Annual Pollutant Load Estimation. J. Environ. Qual., 44(6): 1843-1851, doi: 10.2134/jeq2015.03.0137.

Pellerin, B.A., Bergamaschi, B.A., Gilliom, R.J., Crawford, C.G., Saraceno, J., Frederick, C.P., Downing, B.D., Murphy, J.C., 2014. High frequency measurement of nitrate concentration in the Lower Mississippi River, USA. Environ. Sci. Technol., 48(21): 12612-12619, doi: 10.1021/es504029c.

Ryberg, K.R., Vecchia, A.V., 2014. waterData: An R Package for Retrieval, Analysis, and Anomaly Calculation of Daily Hydrologic Time Series Data. R package version 1.0.4.

Sanford, W.E., Pope, J.P., 2013. Quantifying Groundwater's Role in Delaying Improvements to Chesapeake Bay Water Quality. Environ. Sci. Technol., 47(23): 13330-13338, doi: $10.1021 / \mathrm{es} 401334 \mathrm{k}$.

Shenk, G.W., Linker, L.C., 2013. Development and Application of the 2010 Chesapeake Bay Watershed Total Maximum Daily Load Model. J. Am. Water Resour. Assoc., 49(5): 1042-1056, doi: 10.1111/jawr.12109.

Sprague, L.A., Hirsch, R.M., Aulenbach, B.T., 2011. Nitrate in the Mississippi River and its tributaries, 1980 to 2008: are we making progress? Environ. Sci. Technol., 45(17): 7209-7216, doi: $10.1021 / \mathrm{es} 201221 \mathrm{~s}$.

Stenback, G.A., Crumpton, W.G., Schilling, K.E., Helmers, M.J., 2011. Rating curve estimation of nutrient loads in Iowa rivers. Journal of Hydrology, 396: 158-169, doi: 10.1016/j.jhydrol.2010.11.006. 
Stow, C.A., Borsuk, M.E., 2003. Assessing TMDL effectiveness using flow-adjusted concentrations: a case study of the Neuse River, North Carolina. Environ. Sci. Technol., 37(10): 2043-2050, doi: 10.1021/es020802p.

Turgeon, J.M.L., Courchesne, F., 2008. Hydrochemical behaviour of dissolved nitrogen and carbon in a headwater stream of the Canadian Shield: relevance of antecedent soil moisture conditions. Hydrol. Process., 22(3): 327-339, doi: 10.1002/hyp.6613.

U.S. Geological Survey, 2015. Surface-water data for the nation. http://dx.doi.org/10.5066/F7P55KJN.

Vecchia, A.V., 2003. Relation between climate variability and stream water quality in the continental United States. Hydrological Science and Technology, 19(1): 77-98.

Vecchia, A.V., 2005. Water-quality trend analysis and sampling design for streams in the Red River of the North Basin, Minnesota, North Dakota, and South Dakota, 1970-2001. Scientific Investigations Report 2005-5224, U.S. Geological Survey, Reston, VA, http://pubs.usgs.gov/sir/2005/5224/.

Vecchia, A.V., Gilliom, R.J., Sullivan, D.J., Lorenz, D.L., Martin, J.D., 2009. Trends in concentrations and use of agricultural herbicides for Corn Belt rivers, 1996-2006. Environ. Sci. Technol., 43(24): 9096-102, doi: 10.1021/es902122j.

Vecchia, A.V., Martin, J.D., Gilliom, R.J., 2008. Modeling Variability and Trends in Pesticide Concentrations in Streams. J. Am. Water Resour. Assoc., 44(5): 1308-1324, doi: 10.1111/j.17521688.2008.00225.x.

Wang, Y.-G., Kuhnert, P., Henderson, B., 2011. Load estimation with uncertainties from opportunistic sampling data - A semiparametric approach. Journal of Hydrology, 396(1-2): 148-157, doi: 10.1016/j.jhydrol.2010.11.003.

Wang, Y.-G., Tian, T., 2013. Sediment concentration prediction and statistical evaluation for annual load estimation. Journal of Hydrology, 482: 69-78, doi: 10.1016/j.jhydrol.2012.12.043.

Wang, Y.-G., Wang, S.S.J., Dunlop, J., 2015. Statistical modelling and power analysis for detecting trends in total suspended sediment loads. Journal of Hydrology, 520: 439-447, doi: 10.1016/j.jhydrol.2014.10.062. 
Warner, S., Kiely, G., Morgan, G., O'Halloran, J., 2009. Does quantifying antecedent flow conditions improve stream phosphorus export estimation? Journal of Hydrology, 378(1-2): 97-104, doi: 10.1016/j.jhydrol.2009.09.009.

Zhang, Q., Ball, W.P., Moyer, D.L., 2016a. Decadal-scale export of nitrogen, phosphorus, and sediment from the Susquehanna River basin, USA: Analysis and synthesis of temporal and spatial patterns. Sci. Total Environ., 563-564: 1016-1029, doi: 10.1016/j.scitotenv.2016.03.104.

Zhang, Q., Brady, D.C., Ball, W.P., 2013. Long-term seasonal trends of nitrogen, phosphorus, and suspended sediment load from the non-tidal Susquehanna River Basin to Chesapeake Bay. Sci. Total Environ., 452-453: 208-221, doi: 10.1016/j.scitotenv.2013.02.012.

Zhang, Q., Brady, D.C., Boynton, W., Ball, W.P., 2015. Long-term Trends of Nutrients and Sediment from the Nontidal Chesapeake Watershed: An Assessment of Progress by River and Season. J. Am. Water Resour. Assoc., 51(6): 1534-1555, doi: 10.1111/1752-1688.12327.

Zhang, Q., Hirsch, R.M., Ball, W.P., 2016b. Long-Term Changes in Sediment and Nutrient Delivery from Conowingo Dam to Chesapeake Bay: Effects of Reservoir Sedimentation. Environ. Sci. Technol., 50(4): 1877-1886, doi: 10.1021/acs.est.5b04073. 
Tables

Table 1. Details of the nine river monitoring sites.

\begin{tabular}{ccccccc}
\hline \multirow{2}{*}{$\begin{array}{c}\text { Station } \\
\text { Number }\end{array}$} & River site & $\begin{array}{c}\text { Drainage } \\
\text { area, mi }\end{array}$ & \multicolumn{4}{c}{ Upstream land use (percent) } \\
\cline { 7 - 8 } 04193500 & $\begin{array}{c}\text { Maumee River at } \\
\text { Waterville, OH }\end{array}$ & 6,330 & 89.9 & 1.2 & 7.3 & 1.6 \\
\hline 03231500 & $\begin{array}{c}\text { Scioto River at } \\
\text { Chillicothe, OH }\end{array}$ & 3,854 & 80.2 & 4.6 & 12.9 & 2.3 \\
\hline 03271601 & $\begin{array}{c}\text { Great Miami River below } \\
\text { Miamisburg, OH }\end{array}$ & 2,685 & 82.1 & 4.7 & 10.3 & 2.9 \\
\hline 04198000 & $\begin{array}{c}\text { Sandusky River near } \\
\text { Fremont, OH }\end{array}$ & 1,251 & 84.1 & 0.9 & 13.0 & 2.0 \\
\hline 04176500 & $\begin{array}{c}\text { River Raisin near Monroe, } \\
\text { MI }\end{array}$ & 1,042 & 79.0 & 2.3 & 14.0 & 4.7 \\
\hline 04208000 & $\begin{array}{c}\text { Cuyahoga River at } \\
\text { Independence, OH }\end{array}$ & 707 & 30.4 & 9.6 & 50.1 & 9.9 \\
\hline 04212100 & $\begin{array}{c}\text { Grand River near } \\
\text { Painesville, OH }\end{array}$ & 685 & 40.0 & 0.9 & 45.2 & 13.1 \\
\hline 04197100 & $\begin{array}{c}\text { Honey Creek at Melmore, } \\
\text { OH }\end{array}$ & 149 & 85.6 & 0.6 & 12.5 & 1.3 \\
\hline 04197170 & Rock Creek at Tiffin, OH & 34.6 & 82.0 & 0.9 & 16.1 & 1.0 \\
\hline
\end{tabular}


Table 2. Temporal coverages of water quality data at the nine river monitoring sites.

\begin{tabular}{ccccccccc}
\hline & \multirow{2}{*}{$\begin{array}{c}\text { First } \\
\text { River site }\end{array}$} & $\begin{array}{c}\text { Last } \\
\text { sampled }\end{array}$ & sampled & \multicolumn{5}{c}{ Total number of sampled days } \\
\cline { 5 - 9 } & day & day & Cl & $\mathrm{NO}_{\mathrm{x}}$ & $\mathrm{TKN}$ & $\mathrm{SRP}$ & $\mathrm{TP}$ & $\mathrm{SS}$ \\
\hline Maumee River at & $1975-$ & $2014-$ & 11,447 & 10,898 & 11,397 & 10,752 & 11,462 & 11,429 \\
Waterville, OH & $01-10$ & $12-31$ & $(345)$ & $(328)$ & $(343)$ & $(324)$ & $(345)$ & $(344)$ \\
\hline Scioto River at & $1996-$ & $2015-$ & 4828 & 4816 & 4812 & 4785 & 4825 & 4803 \\
Chillicothe, OH & $04-23$ & $01-03$ & $(258)$ & $(258)$ & $(257)$ & $(256)$ & $(258)$ & $(257)$ \\
\hline Great Miami River & $1996-$ & $2015-$ & 6356 & 6357 & 6309 & 6317 & 6349 & 6333 \\
below Miamisburg, & $04-22$ & $04-04$ & $(335)$ & $(335)$ & $(333)$ & $(333)$ & $(335)$ & $(334)$ \\
OH & & & & & & & \\
Sandusky River & $1974-$ & $2014-$ & 12,055 & 12,054 & 10,719 & 11,319 & 12,363 & 12,315 \\
near Fremont, OH & $10-02$ & $12-31$ & $(301)$ & $(300)$ & $(275)$ & $(281)$ & $(307)$ & $(306)$ \\
\hline River Raisin near & $1982-$ & $2014-$ & 8,268 & 8,213 & 8,228 & 7,621 & 8,269 & 8,236 \\
Monroe, MI & $03-06$ & $12-31$ & $(281)$ & $(279)$ & $(280)$ & $(259)$ & $(281)$ & $(280)$ \\
\hline Cuyahoga River at & $1981-$ & $2014-$ & 10,856 & 10,890 & 10,838 & 10,627 & 10,896 & 10,862 \\
Independence, OH & $11-04$ & $12-31$ & $(327)$ & $(329)$ & $(327)$ & $(321)$ & $(329)$ & $(328)$ \\
\hline Grand River near & $1988-$ & $2006-$ & 5,621 & 5,435 & 5,545 & 4,977 & 5,598 & 5,565 \\
Painesville, OH & $02-16$ & $08-10$ & $(304)$ & $(294)$ & $(300)$ & $(269)$ & $(303)$ & $(301)$ \\
\hline Honey Creek at & $1976-$ & $2014-$ & 11,604 & 11,617 & 11,353 & 10,647 & 11,623 & 11,499 \\
Melmore, OH & $01-28$ & $12-31$ & $(342)$ & $(343)$ & $(342)$ & $(314)$ & $(343)$ & $(339)$ \\
\hline Rock Creek at & $1982-$ & $2014-$ & 9,249 & 8,911 & 9,202 & 8,697 & 9,251 & 9,191 \\
Tiffin, OH & $10-11$ & $12-31$ & $(349)$ & $(336)$ & $(347)$ & $(328)$ & $(349)$ & $(347)$ \\
\hline
\end{tabular}

Table 3. Summary of cases with major improvements in model estimation performance. Each case shows results from on one selected model run.

\begin{tabular}{cccccccc}
\hline \multirow{2}{*}{ Case } & \multirow{2}{*}{ Model } & \multicolumn{3}{c}{ Concentration } & \multicolumn{3}{c}{ Flux } \\
\cline { 3 - 8 } & & NSE & E & PBIAS & NSE & E & PBIAS \\
\hline Grand River & Original Model & 0.28 & 0.18 & 2.3 & 0.73 & 0.63 & -2.2 \\
\cline { 2 - 8 } NO $_{\mathrm{x}}$ & LTFA Model & 0.41 & 0.27 & 1.7 & 0.83 & 0.71 & 0.83 \\
\hline Maumee River Cl & Original Model & 0.54 & 0.36 & 0.46 & 0.83 & 0.72 & 1.7 \\
\cline { 2 - 8 } & STFA Model & 0.77 & 0.54 & 0.43 & 0.89 & 0.77 & 1.3 \\
\hline
\end{tabular}


Figures

(a)

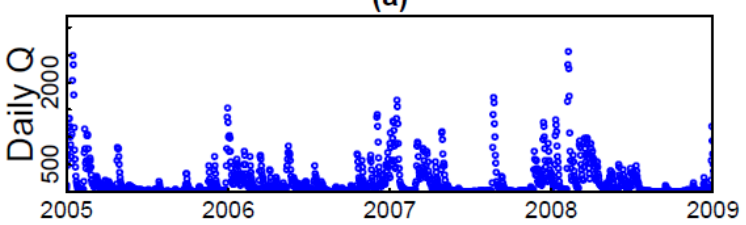

(b)

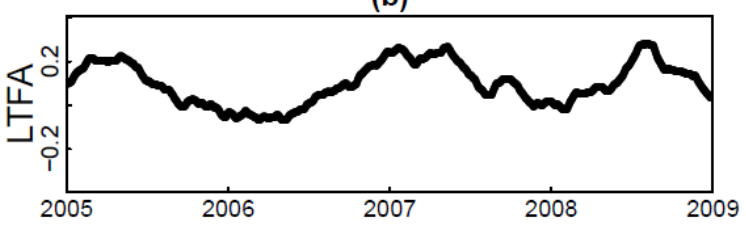

(d)

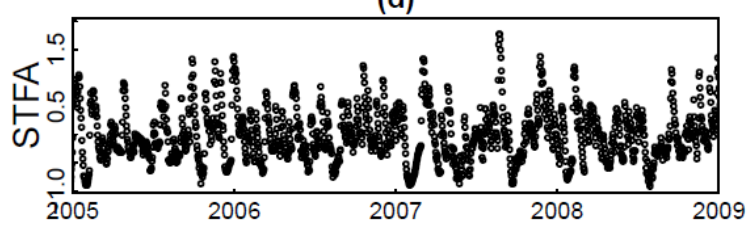

(f)

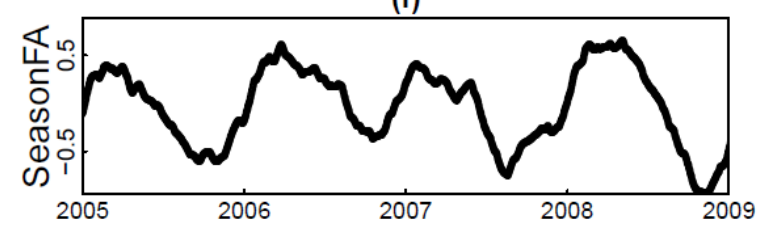

(h)

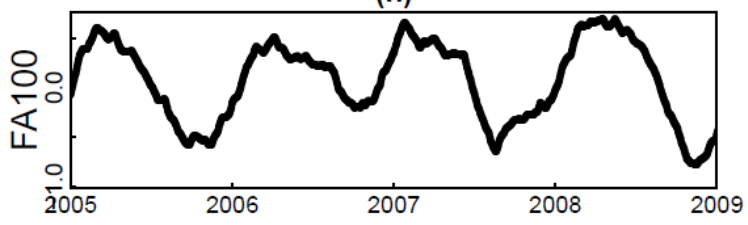

(j)

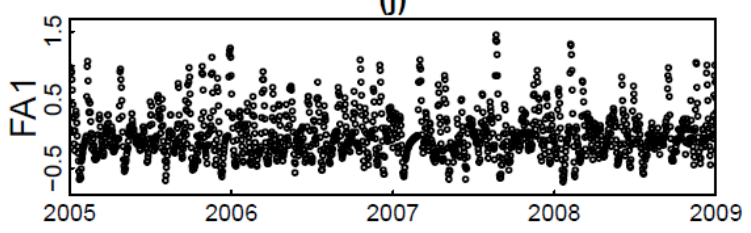

(I)

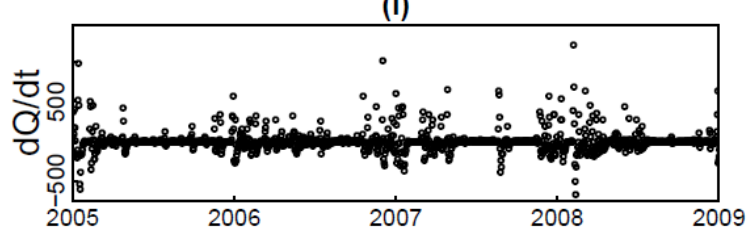

(a)

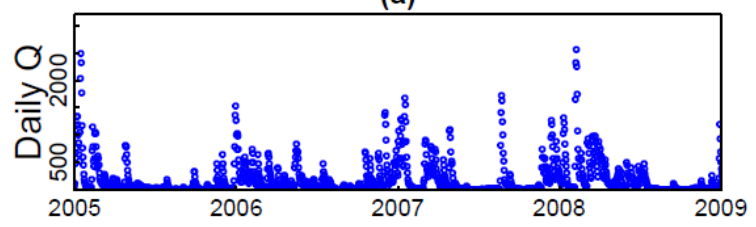

(c)

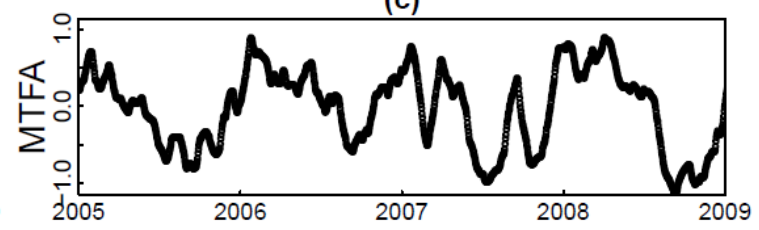

(e)

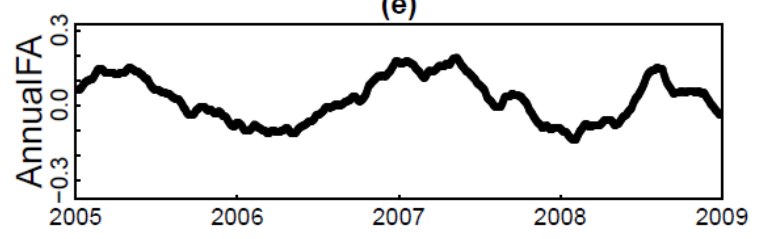

(g)

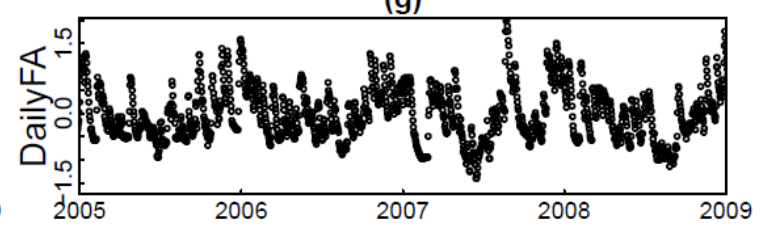

(i)

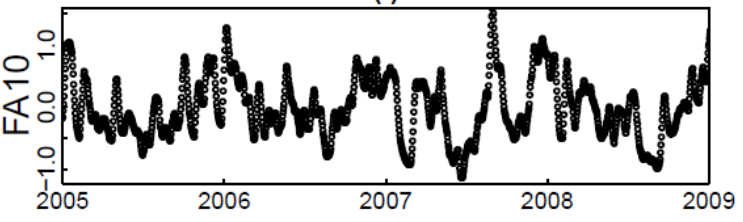

(k)
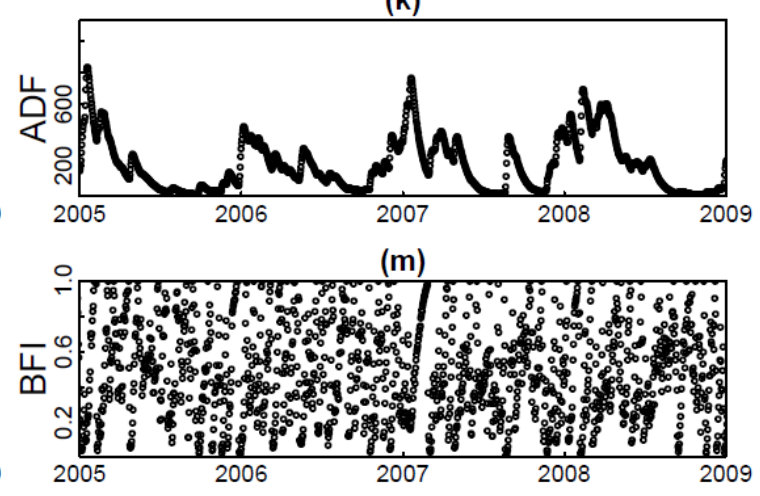

Fig. 1. Time series of (a) observed daily discharge and (b-m) derived antecedent discharge variables for Maumee River at Waterville, OH. Only the period of 2005-2009 is shown for visual clarity. Panel (a) is repeated in both columns to aid comparison with the derived flow variables. 
(a) All Samples

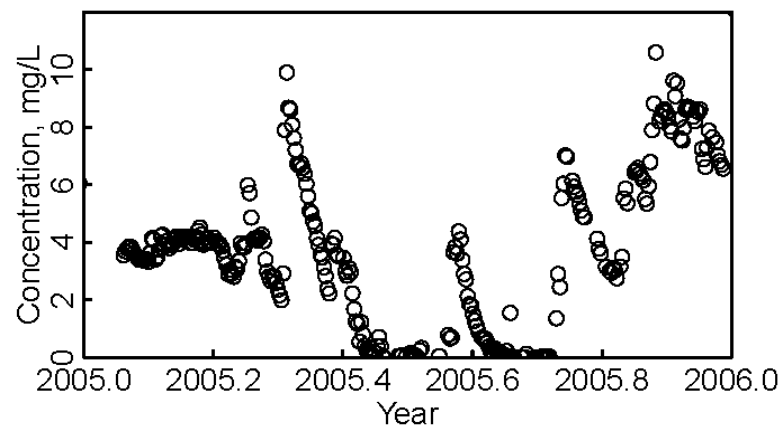

(c) 20 Random

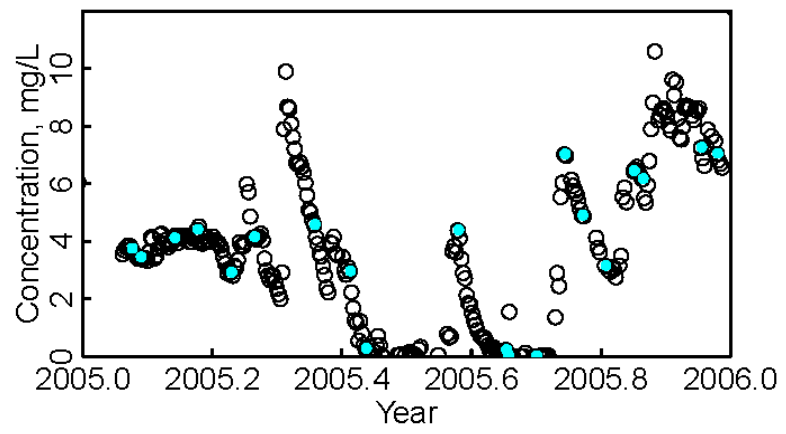

(b) 12 Random

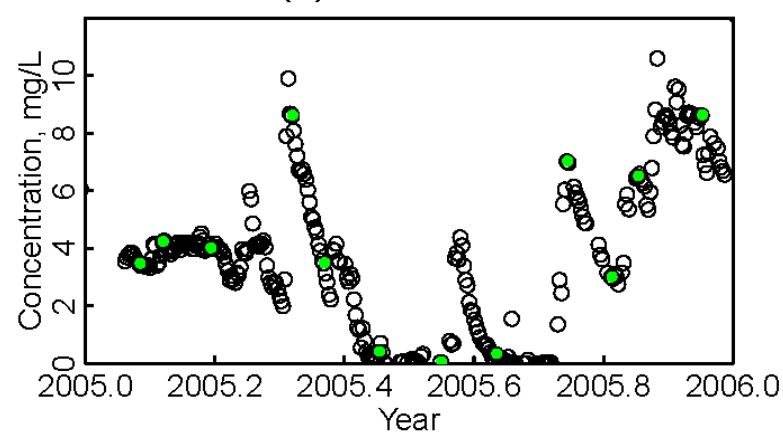

(d) 12 Regular +8 Storm

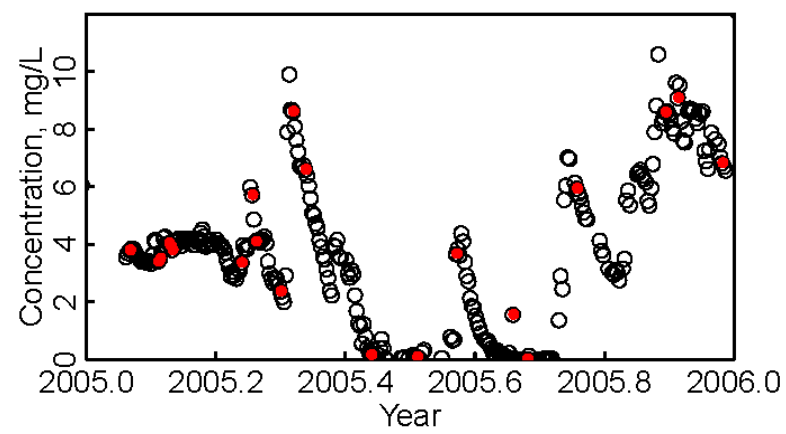

Fig. 2. Example time series of (a) the original $\mathrm{NO}_{\mathrm{x}}$ concentration data (black open circle) and (bd) three types of concentration subsets (non-black solid circle) in Maumee River at Waterville, $\mathrm{OH}$ between 2005 and 2006. Panels (b), (c), and (d) correspond to sampling strategies A, B, and $\mathrm{C}$, respectively. See text for details. 

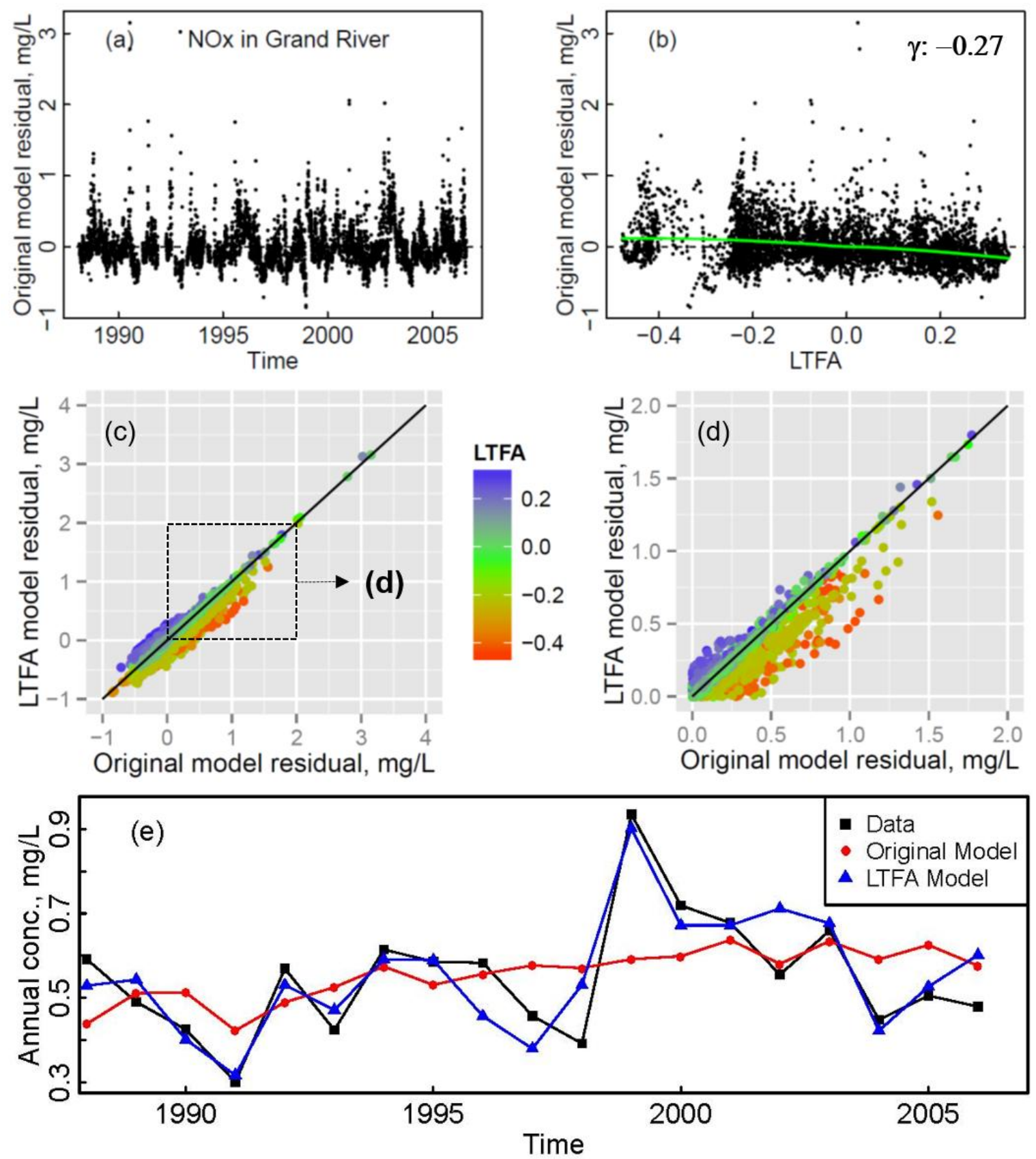

Fig. 3. Comparison of the original WRTDS model and the LTFA (long-term flow anomaly) model for $\mathrm{NO}_{\mathrm{x}}$ in Grand River near Painesville, $\mathrm{OH}$. (a) Time series of residuals from the original model. (b) Relationship between the original model residuals and LTFA, as modeled with LOWESS curve (green line). Spearman's correlation coefficient $(\gamma)$ is shown on the plot. (c) Comparison between the LTFA model residuals and the original model residuals. (d) An enlarged view of the first quadrant of panel (c). (e) Time series of annual concentration based on observed data, the original model, and the LTFA model. 

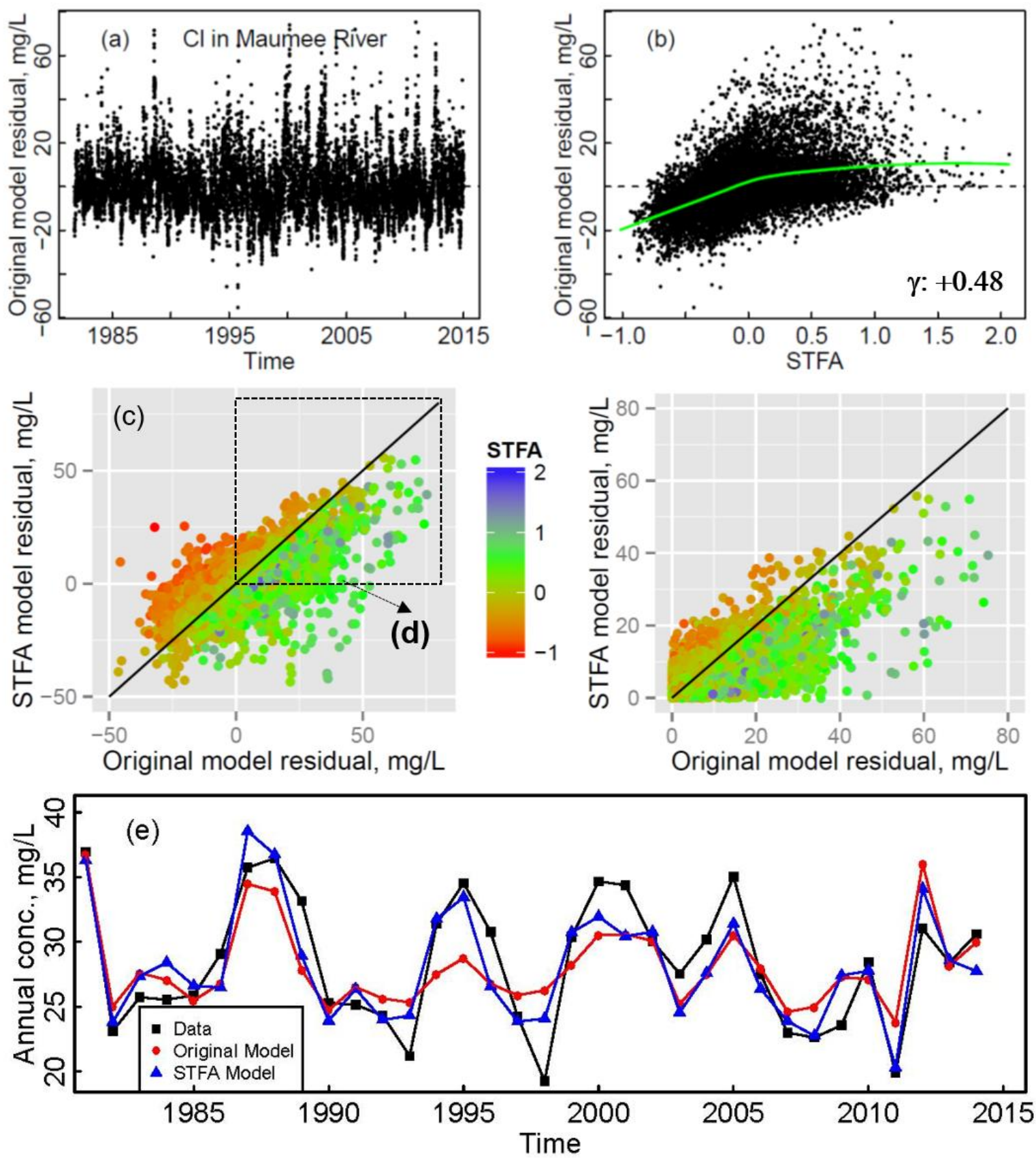

Fig. 4. Comparison of the original WRTDS model and the STFA (short-term flow anomaly) model for $\mathrm{Cl}$ in Maumee River at Waterville, $\mathrm{OH}$. (a) Time series of residuals from the original model. (b) Relationship between the original model residuals and STFA, as modeled with LOWESS curve (green line). Spearman's correlation coefficient $(\gamma)$ is shown on the plot. (c) Comparison between the STFA model residuals and the original model residuals. (d) An enlarged view of the first quadrant of panel (c). (e) Time series of annual concentration based on observed data, the original model, and the STFA model. 

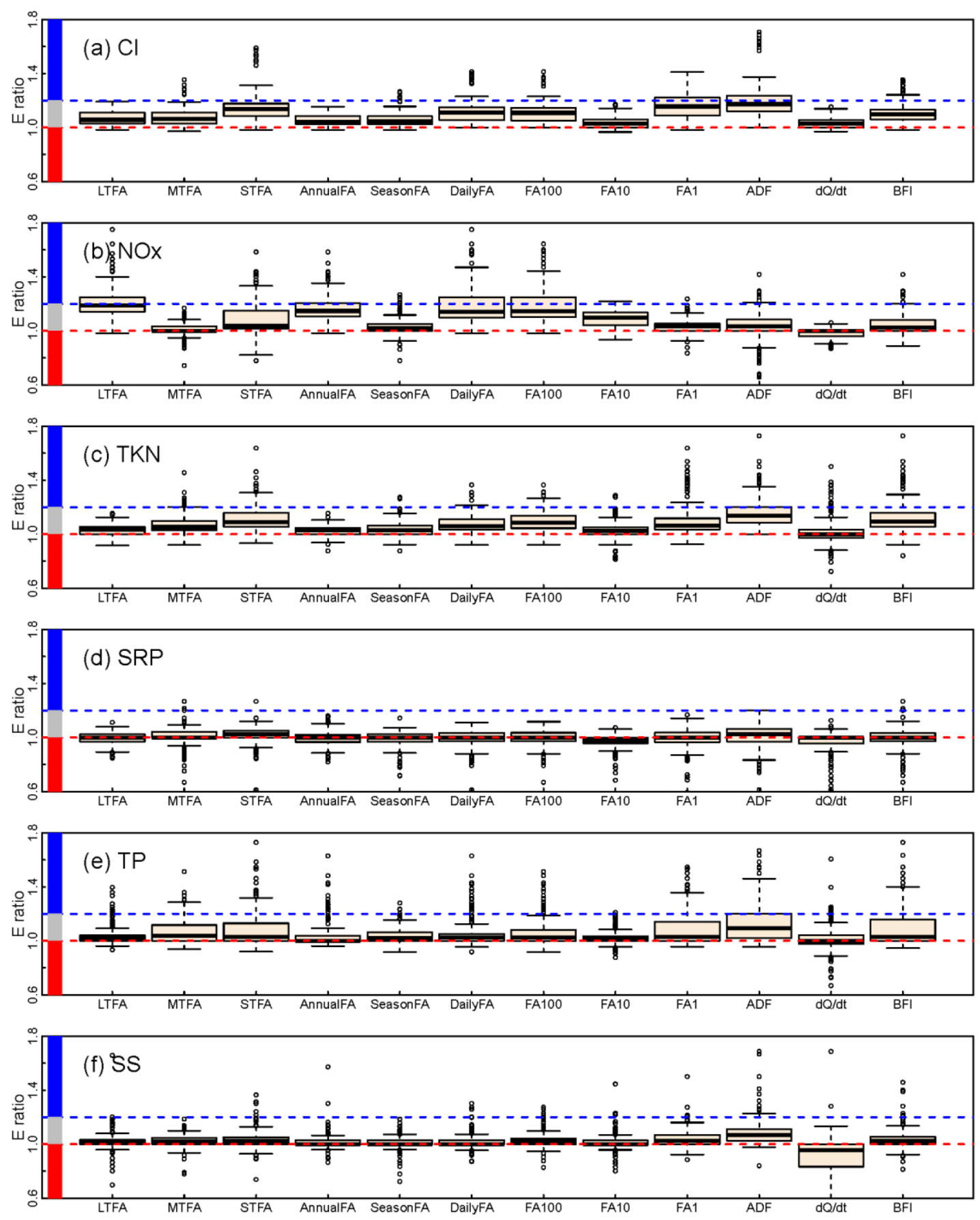

Fig. 5. Boxplots of the ratio between the modified Nash-Sutcliffe efficiency (E) of each modified model and E-value of the original WRTDS model for the nine study sites for (a) $\mathrm{Cl}$, (b) $\mathrm{NO}_{\mathrm{x}}$, (c) TKN, (d) SRP, (e) TP, and (f) SS. The E-value ratios are divided into three regions: (1) major improvement (ratio > 1.2; blue bar), (2) minor improvement $(1<$ ratio < 1.2; grey bar), and (3) inferior performance (ratio < 1.0; red bar). Each boxplot represents 30 replicates at each of the nine sites (i.e., 270 cases) under sampling strategy A. 

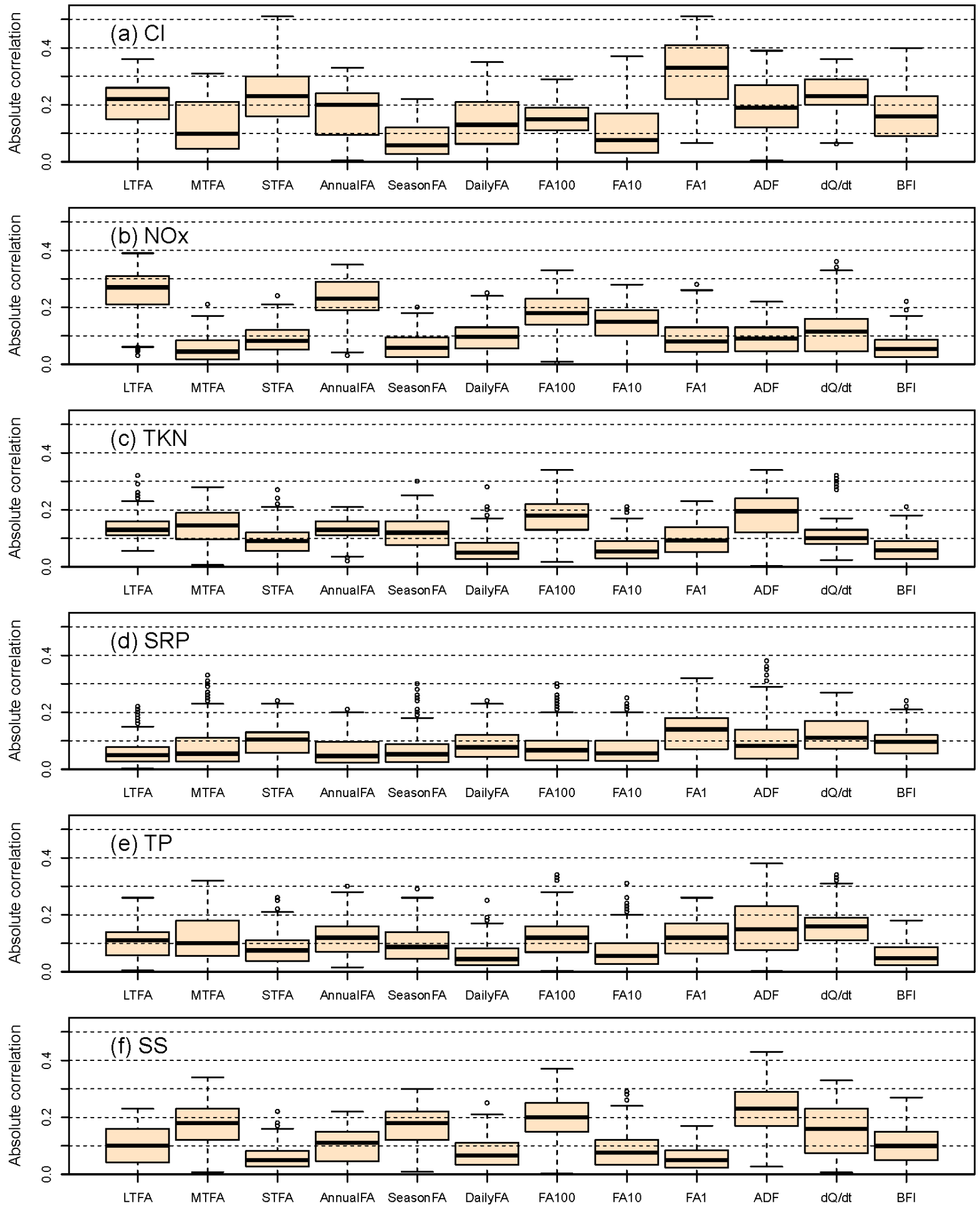

Fig. 6. Boxplots of the absolute value of Spearman's correlation $(|\gamma|)$ between residuals from the original WRTDS model and each of the twelve proposed flow variables. Each boxplot represents 30 replicates at each of the nine sites (i.e., 270 cases) under sampling strategy A. 

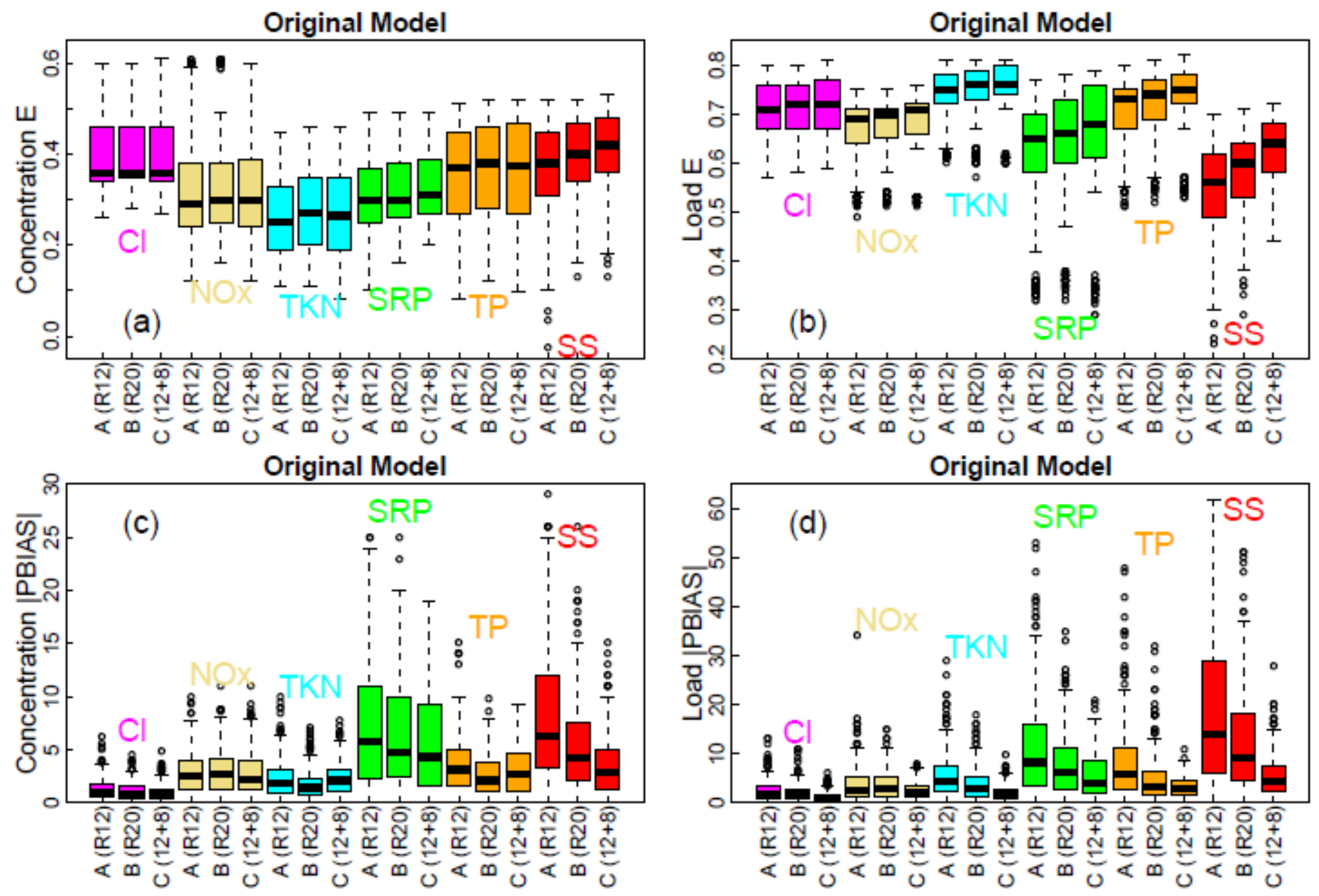

Fig. 7. Performance of the original WRTDS model under each of the three sampling strategies. The performance is quantified with modified Nash-Sutcliffe efficiency (E) for (a) concentration and (b) flux and with absolute percent bias (|PBIAS|) for (c) concentration and (d) flux. Each boxplot represents 30 replicates at each of the nine sites (i.e., 270 cases) under each sampling strategy. 


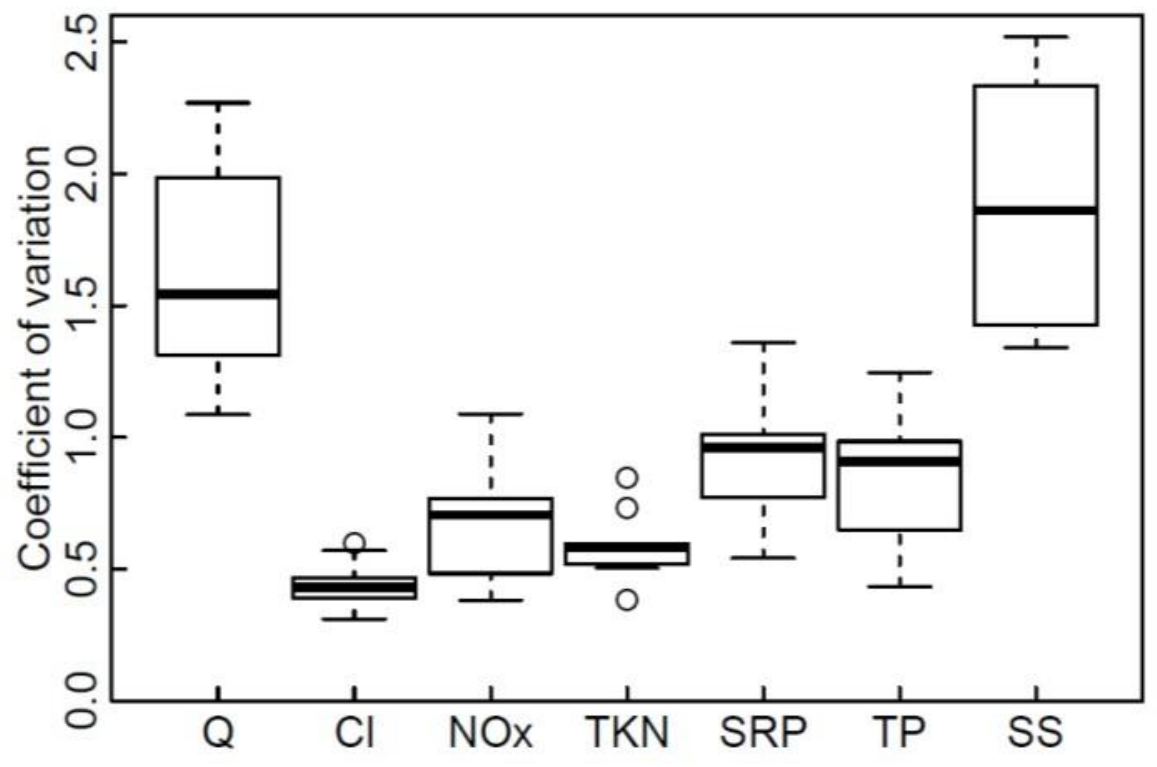

Fig. 8. Boxplots of the coefficient of variation in observed daily discharge (Q) and constituent concentration data. Each boxplot summarizes nine coefficients, each of which is based on monitoring data at one of the nine sites. 

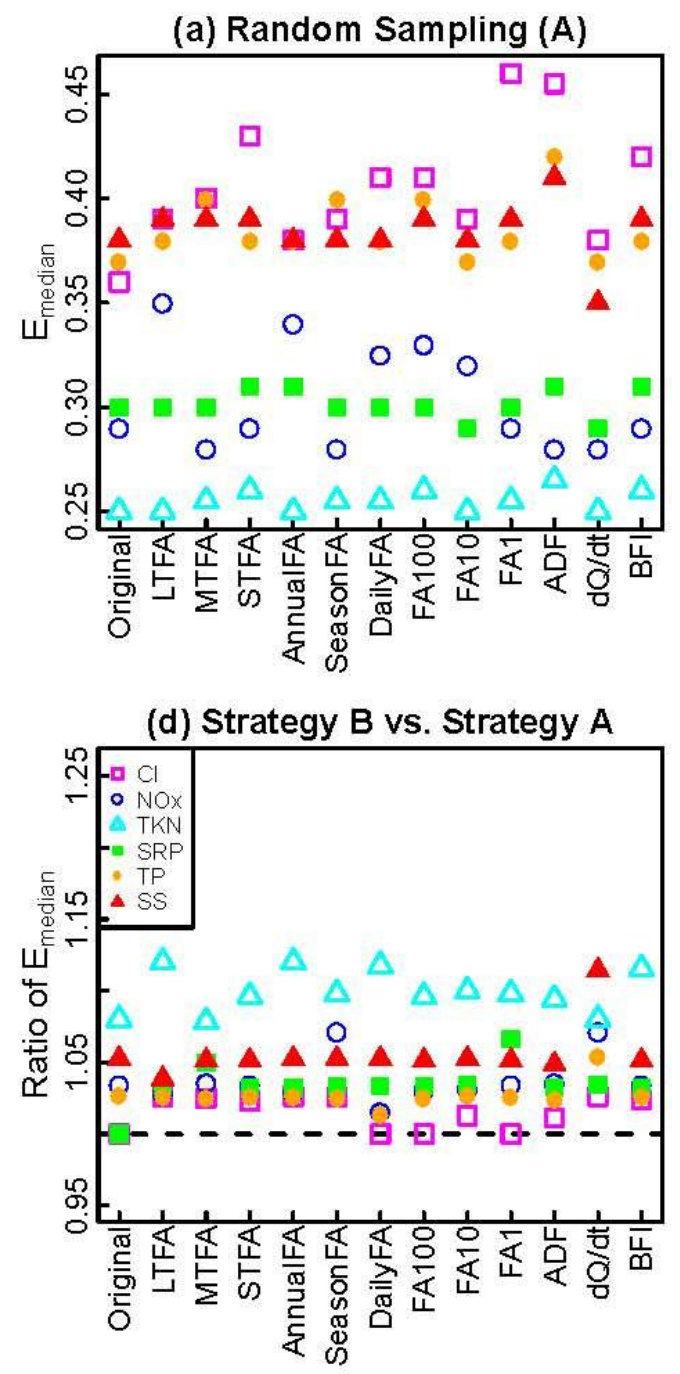

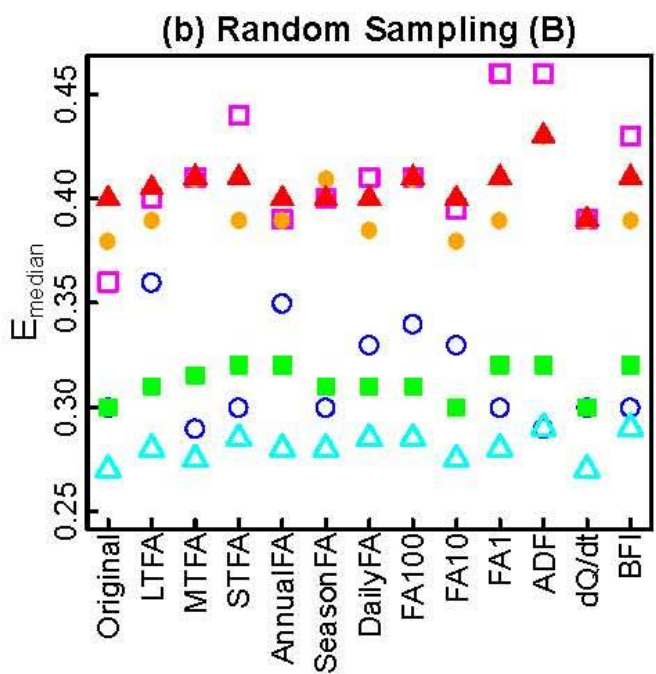

(e) Strategy C vs. Strategy A

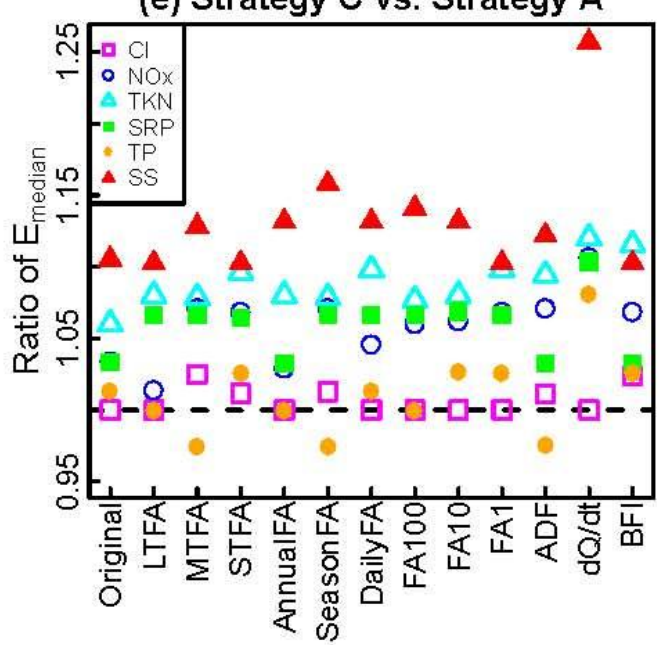

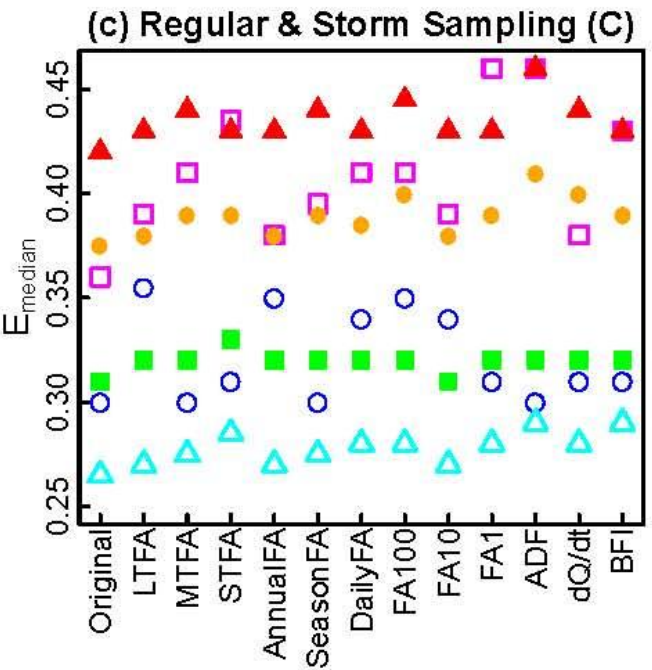

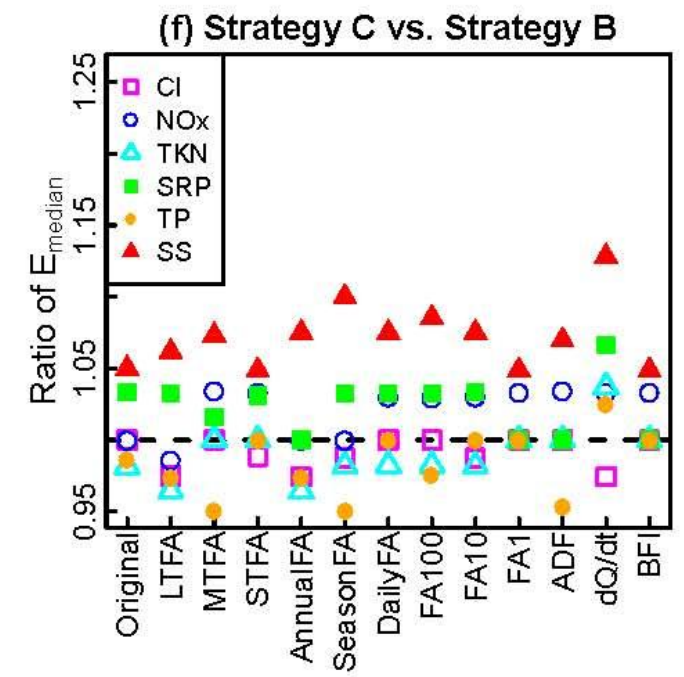

Fig. 9. Performance of the original and modified WRTDS models under the three sampling strategies. Panels (a)-(c) summarizes the performance with medians of modified Nash-Sutcliffe efficiency (E) for concentration based on 30 replicates at each of the nine sites (i.e., 270 cases) under each sampling strategy. Panels (d)-(f) compares the three sampling strategies directly using ratios of E median. 

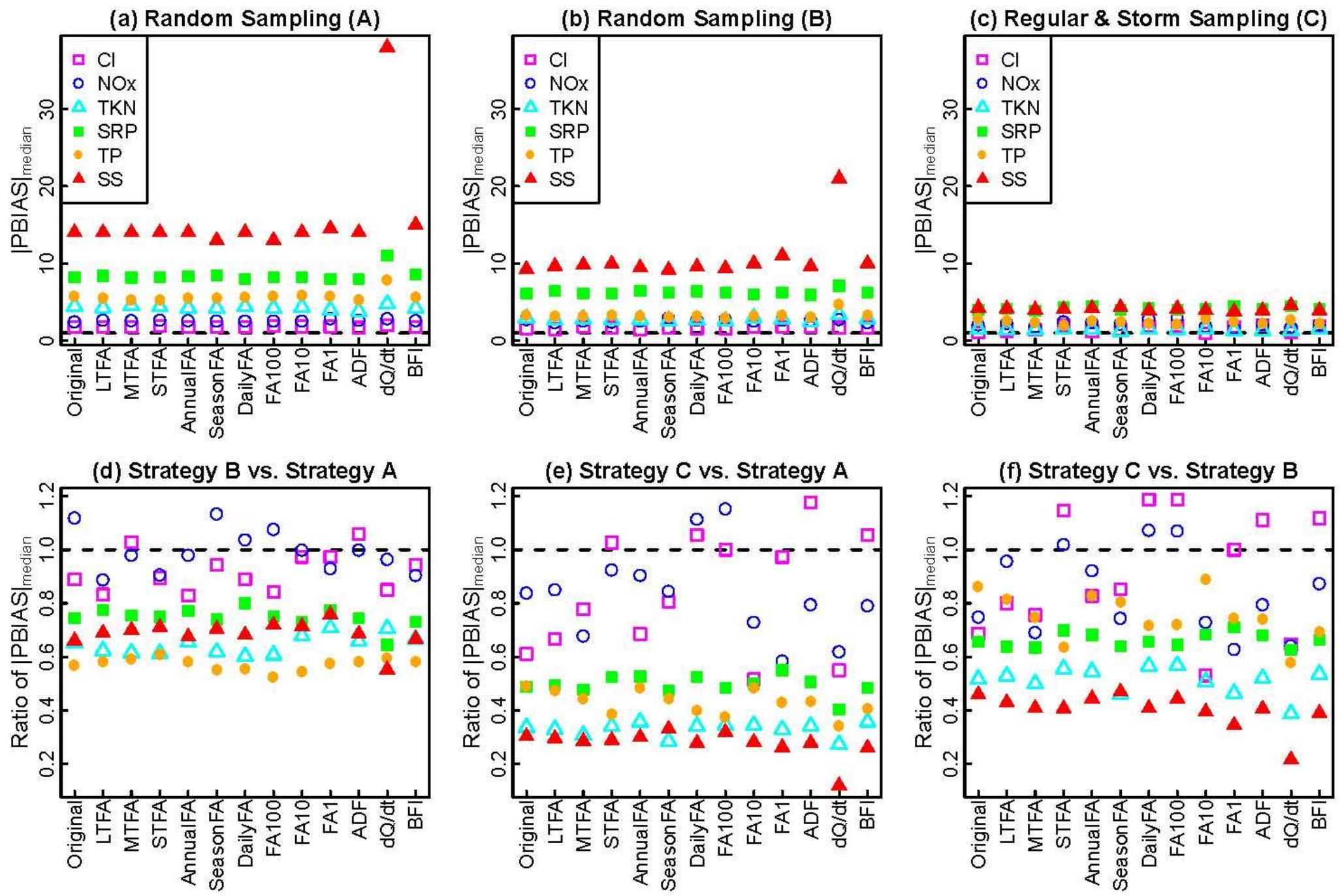

Fig. 10. Performance of the original and modified WRTDS models under the three sampling strategies. Panels (a)-(c) summarizes the performance with medians of absolute value of percent bias (|PBIAS|) for flux based on 30 replicates at each of the nine sites (i.e., 270 cases) under each sampling strategy. Panels (d)-(f) compares the three sampling strategies directly using ratios of |PBIAS| median. 